\title{
Simulations of two types of El Niño events by an optimal forcing vector approach
}

\author{
Wansuo Duan $\cdot$ Ben Tian $\cdot$ Hui Xu
}

Received: 19 June 2013/Accepted: 31 October 2013/Published online: 26 November 2013

(C) The Author(s) 2013. This article is published with open access at Springerlink.com

\begin{abstract}
In this paper, an optimal forcing vector (OFV) approach is proposed. The OFV offsets tendency errors and optimizes the agreement of the model simulation with observation. We apply the OFV approach to the wellknown Zebiak-Cane model and simulate several observed eastern Pacific (EP) El Niño and central Pacific (CP) El Niño events during 1980-2004. It is found that the ZebiakCane model with a proper initial condition often reproduces the EP-El Niño events; however, the Zebiak-Cane model fails to reproduce the CP-El Niño events. The model may be much more influenced by model errors when simulating the CP-El Nino events. As expected, when we use the OFV to correct the Zebiak-Cane model, the model reproduces the three CP-El Niño events well. Furthermore, the simulations of the corresponding winds and thermocline depths are also acceptable. In particular, the thermocline depth simulations for the three CP-El Niño events lead us to believe that the discharge process of the equatorial heat content associated with the CP-El Niño is not efficient and emphasizes the role of the zonal advection in the development of the CP-El Nino events. The OFVs associated with the three CP-El Niño events often exhibit a sea surface temperature anomaly (SSTA) tendency with positive anomalies in the equatorial eastern Pacific; therefore, the SST tendency errors occurring in the equatorial eastern Pacific may dominate the uncertainties of the Zebiak-Cane model while simulating CP-El Nino events.
\end{abstract}

W. Duan · B. Tian · H. Xu (ه)

LASG, Institute of Atmospheric Physics, Chinese Academy

of Sciences, Beijing 100029, China

e-mail: xuh@lasg.iap.ac.cn

B. Tian

University of Chinese Academy of Sciences,

Beijing 100049, China
A further investigation demonstrates that one of the model errors offset by the OFVs is of a pattern similar to the SST cold-tongue cooling mode, which may then provide one of the climatological conditions for the frequent occurrence of CP-El Nino events. The OFV may therefore be a useful tool for correcting forecast models and then for helping improve the forecast skill of the models.

Keywords Optimal forcing vector - Model error . El Nino events · Numerical simulation

\section{Introduction}

El Nino-Southern Oscillation (ENSO) events are characterized by an interannual variation of the sea surface temperature (SST) over the eastern-to-central tropical Pacific and have received much attention for both their climatic and economic effects (Rasmusson and Carpenter 1982; Barber and Chavez 1983; Cane 1983; Rasmusson and Wallace 1983). The canonical El Niño event portrayed by Rasmusson and Carpenter (1982) typically develops from the South American coast and propagates westward across the tropical Pacific. Recent studies have shown that canonical El Niño events have become less frequent and that a different type of El Niño has become more common during the late twentieth century, especially after the 1990s (Ashok et al. 2007; Kao and Yu 2009; Kug et al. 2009); in this type, warm SST is mainly concentrated in the central Pacific and does not propagate. The new type of El Niño events significantly influences the temperature and precipitation over many parts of the globe but in a different manner from canonical El Niño events (e.g. Weng et al. 2007). Here, we follow the convention of previous papers in using "EP-El Niño" and "CP-El Niño" to denote the 
canonical El Niño events and the new type of El Niño events, respectively.

Many models fail to simulate the CP-El Niño, and certain models even have problems depicting some aspects of the EP-El Niño, such as phase locking and long-term variability. For the models that can capture the CP-El Niño SST anomaly pattern to some extent (Kug et al. 2010), the SST interannual variability may be overestimated not only in the eastern Pacific but also in the central-western Pacific. The location of the strong SST variability in most CGCMs shifts further westward than observed; therefore, the area used to define the CP-El Niño turns westward (Kug et al. 2010). Kim et al. (2012) examined the performance of the National Centers for Environmental Prediction (NCEP) Climate Forecast System (CFS) model for the two types of El Niño. They found that the ENSO intensity is weaker than observed for the CP-El Niño and that the weaker CPEl Niño events in the model are also partially due to unrealistically weak zonal advection feedback in the equatorial Pacific, which is quite different from observations (Ashok et al. 2007; Kao and Yu 2009; Kug et al. 2009). Therefore, some models may have more uncertainties in simulating CP-El Nino events than in simulating EP-El Nino events.

In this paper, we will try to simulate the observed El Nino events by conducting observation system simulation experiments (OSSEs; Arnold and Dey 1986; Lord et al. 1997; Atlas 1997). Generally, the simulation uncertainties in OSSEs are caused by both initial and model errors. In numerical weather forecasting and climate prediction, several methods, such as the variational data assimilation (Talagrand 1997), the Ensemble Kalman Filter (Evensen 1994) and target observation methods (Morss et al. 2001), have been proposed for reducing the uncertainties of the initial conditions. Meteorologists are also seeking ways to minimize the model errors to improve their predictability. Efforts to reduce model errors have included improving the resolutions of the models, parameterizing the physical processes, and using computer technology with greater accuracy. More skillfully, D'Andrea and Vautard (2000) applied an appropriate constant external forcing to the tendency equations of a model and corrected the model closest to the observations, thereby generating a perturbed model to improve the forecast results. Roads (1987) and Vannitsem and Toth (2002) also used a similar approach to reducing the effects of model errors. In fact, if only timeinvariant tendency errors exist in the models, a constant external forcing may be useful and can offset the effect of model errors induced by the tendency errors; here, the constant forcing sensitivity vectors (FSVs) proposed by Barkmeijer et al. (2003) potentially reduce the model error effects by the largest extent. Feng and Duan (2013) demonstrated that constant FSVs could also offset some of the time-variant tendency errors, but large time-variant tendency errors remain and cannot be eliminated. Therefore, it is necessary to find a more effective approach to offsetting the time-variant tendency errors and reducing the effects of the model errors, which, together with a proper initialization procedure, may bring the ENSO model simulation closer to the observation (see Sect. 2).

In this study, we will propose an optimal forcing vector (OFV) approach that can correct a model and apply it to the well-known Zebiak and Cane model (1987) to reproduce observed ENSO events. The focus is on investigating the role of OFV in offsetting the model errors to improve the simulation of El Niño events. Section 2 proposes the OFV approach as well as describes the related calculations. Section 3 applies the OFV approach to the simulation of the observed El Niño events and identifies the source of the uncertainties that influence the El Nino simulations. Section 4 is reserved for discussing the implications of the OFV to the occurrences of CP-El Niño events. Finally, we present a summary and discussion in Sect. 5.

\section{The optimal forcing vector}

Consider a nonlinear partial differential equation:

$\left\{\begin{array}{l}\frac{\partial \mathbf{u}}{\partial t}=F(\mathbf{u}, t), \\ \left.\mathbf{u}\right|_{t=0}=\mathbf{u}_{0},\end{array}\right.$

where $\mathbf{u}(\mathbf{x}, t)=\left[u_{1}(\mathbf{x}, t), u_{2}(\mathbf{x}, t), \ldots, u_{n}(\mathbf{x}, t)\right]$ is the state vector, $F$ is a nonlinear operator, $\mathbf{u}_{0}$ is the initial state, $(\mathbf{x}, t) \in \Omega \times[0, T], \Omega$ is a domain in $R^{n}, T<+\infty, \mathbf{x}=$ $\left(x_{1}, x_{2}, \ldots, x_{n}\right)$, and $t$ is the time. For the given initial field $\mathbf{u}_{0}$, the solution to Eq. (1) for the state vector $\mathbf{u}$ at time $\tau$ is given by

$\mathbf{u}(\mathbf{x}, \tau)=M_{\tau}\left(\mathbf{u}_{0}\right)$.

Suppose we use the model described by Eq. (1) to predict the motion of the atmosphere or oceans; however, the errors are associated with the model and then yield predictions uncertainties.

D'Andrea and Vautard (2000) reduced model errors by adding an optimal constant forcing $\mathbf{f}(\mathbf{x})$ to offset the model tendency errors. However, tendency errors are generally time-variant. Although an optimal constant forcing can offset a fraction of the time-variant tendency errors (Feng and Duan 2013), large time-variant tendency errors remain. Therefore, we consider superimposing a time-variant external forcing to offset the model error effects; we need to obtain a proper external forcing $\mathbf{f}(\mathbf{x}, t)$ for Eq. (3) to make the model agree with the observation.

$\left\{\begin{array}{l}\frac{\partial \mathbf{u}}{\partial t}=F(\mathbf{u}, t)+\mathbf{f}(\mathbf{x}, t), \\ \left.\mathbf{u}\right|_{t=0}=\mathbf{u}_{0} .\end{array}\right.$ 
Thus, we transform this problem into a type of nonlinear optimization problem. The optimization problem can consider that certain $\mathbf{f}(\mathbf{x}, t)$ are chosen such that the differences between the model simulation and the observations are minimized. That is, we should find an external forcing that satisfies the following optimization problem

$J\left(f_{\min , t_{i}}\right)=\min \left\|M_{t_{i+1}-t_{i}}\left(f_{t_{i}}\right)\left(\mathrm{u}_{t_{i}}\right)-\mathrm{u}_{t_{i+1}}^{o b s}\right\|$,

where $t_{i}, t_{i+1} \in\left[t_{0}, t_{k}\right], M_{t_{i+1}-t_{i}}\left(f_{t_{i}}\right)$ is the propagator of Eq. (3) from time $t_{i}$ to $t_{i+1}$ and $\mathrm{u}_{t_{i}}=M_{t_{i}-t_{i-1}}\left(f_{\min , t_{i-1}}\right)\left(\mathrm{u}_{t_{i-1}}\right)$. Note that the time interval $\left[t_{i}, t_{i+1}\right]$ is not necessary to be a time step of numerical integration, but may represent several days, a month, a season or others. An external forcing (vector) $f_{\min , t_{k}-t_{0}}=\left(f_{\min , t_{0}}, f_{\min , t_{1}}, f_{\min , t_{2}}, \ldots\right.$, $\left.f_{\min , t_{k-1}}\right)$ can be obtained from Eq. (4). This forcing vector $f_{\min , t_{k}-t_{0}}$ is the $\mathrm{OFV}$, which, as mentioned in introduction, produces the model simulation closest to the observation during the time window $\left[t_{0}, t_{k}\right]$.

It is clear that for a given norm, Eq. (4) defines an unconstrained optimization problem, with the OFV $f_{\min , t_{k}-t_{0}}$ being the minimum point of the objective function in the phase space. We note that the OFV is still timeindependent during the time interval $\left[t_{i}, t_{i+1}\right]$. Therefore, the OFV can be computed as constant FSV proposed by Barkmeijer et al. (2003) by using the limited memory Broyden-Fletcher-Goldfarb-Shanno (L-BFGS; Liu and Nocedal 1989) algorithm. This solver adopts the gradientsteepest descent method and finds the minimum value of an objective function, in which one needs to calculate the gradient of the objective function with respect to the external forcing. Feng and Duan (2013) provided the approach of numerically computing the gradient of the objective function with respect to the external forcing. We refer readers to the paper of Feng and Duan (2013) for the details of this approach. Using this gradient information, we can compute the OFV of a numerical model using the L-BFGS solver.

\section{Application of the OFV approach to simulating the two types of El Niño events}

As mentioned in the introduction, many models fail to simulate the CP-El Niño events and even have problems describing certain aspects of the EP-El Niño events. The difficulties may arise due to the effects of model errors. In this section, we will investigate the OFVs of the ZebiakCane model and explore the role of the OFVs in correcting the model and then reproducing the two observed types of El Niño events.

\subsection{Model and data}

We use the Zebiak-Cane model to study the role of OFVs in reproducing El Niño events. The Zebiak-Cane model was the first coupled ocean-atmosphere model to simulate the observed ENSO interannual variability and has provided a benchmark in ENSO research for decades (Zebiak and Cane 1987; Blumenthal 1991; Xue et al. 1994; Chen et al. 2004; Tang et al. 2008). The model is composed of a Gill-type steady-state linear atmospheric model and a reduced-gravity oceanic model, which depict the thermodynamics and atmospheric dynamics of the tropical Pacific with oceanic and atmospheric anomalies near the mean climatological state specified from observations (see $\mathrm{Ze}$ biak and Cane 1987). The Zebiak-Cane model has been widely used to study ENSO dynamics and predictabilities, but these studies focused on EP-El Niño events. Still, there are much fewer papers using the Zebiak-Cane model to simulate the CP-El Niño events, largely because the Zebiak-Cane model cannot reproduce CP-El Nino events due to the effects of model errors. The OFV could offset tendency errors and correct the model to agree with the observations. In this paper, we will use the Zebiak-Cane model to explore the simulation of the two types of observed El Niño, especially the CP-El Niño events.

As seen in Eq. (4), the OFV approach requires observational data. For the observed El Niño events, we extract the SST data from the Hadley Centre Global Sea Ice and Sea Surface Temperature (HadISST) analyses data sets (Rayner et al. 2003) from January 1980 to December 2010. The adopted wind data are from the National Center for Environmental Prediction/National Center for Atmospheric Research (NCEP/NCAR) reanalysis products (Kalnay et al. 1996). The monthly wind stress anomalies from 1978 to 2006 used to initialize the ZC model are derived from Florida State University analyses (Bourassa et al. 2001). The GODAS depth of $20{ }^{\circ} \mathrm{C}$ from the NOAA NCEP EMC CMB Pacific is also used (Behringer et al. 1998). The data (hereafter referred to as the EMC/CMB data) are derived from a model-based ocean analysis system, and we used the period from 1980 to 2008 .

\subsection{Simulations of the two types of El Niño events}

There are several EP- and CP-El Niño events during 1980-2004. In this paper, we choose three EP-El Niño years of 1982, 1987 and 1997 (see Fig. 1) and three CP-El Niño years of 1990, 2002, and 2004 (see Fig. 2) and then investigate the role of the OFV in simulating the two types of El Niño events.

For each El Niño event, we compute the corresponding OFV according to Eq. (4). We use the initialization 


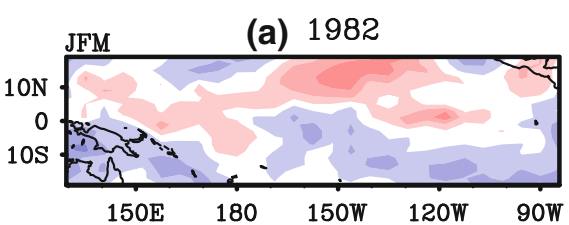

Three EP-El Nino SST Anomaly
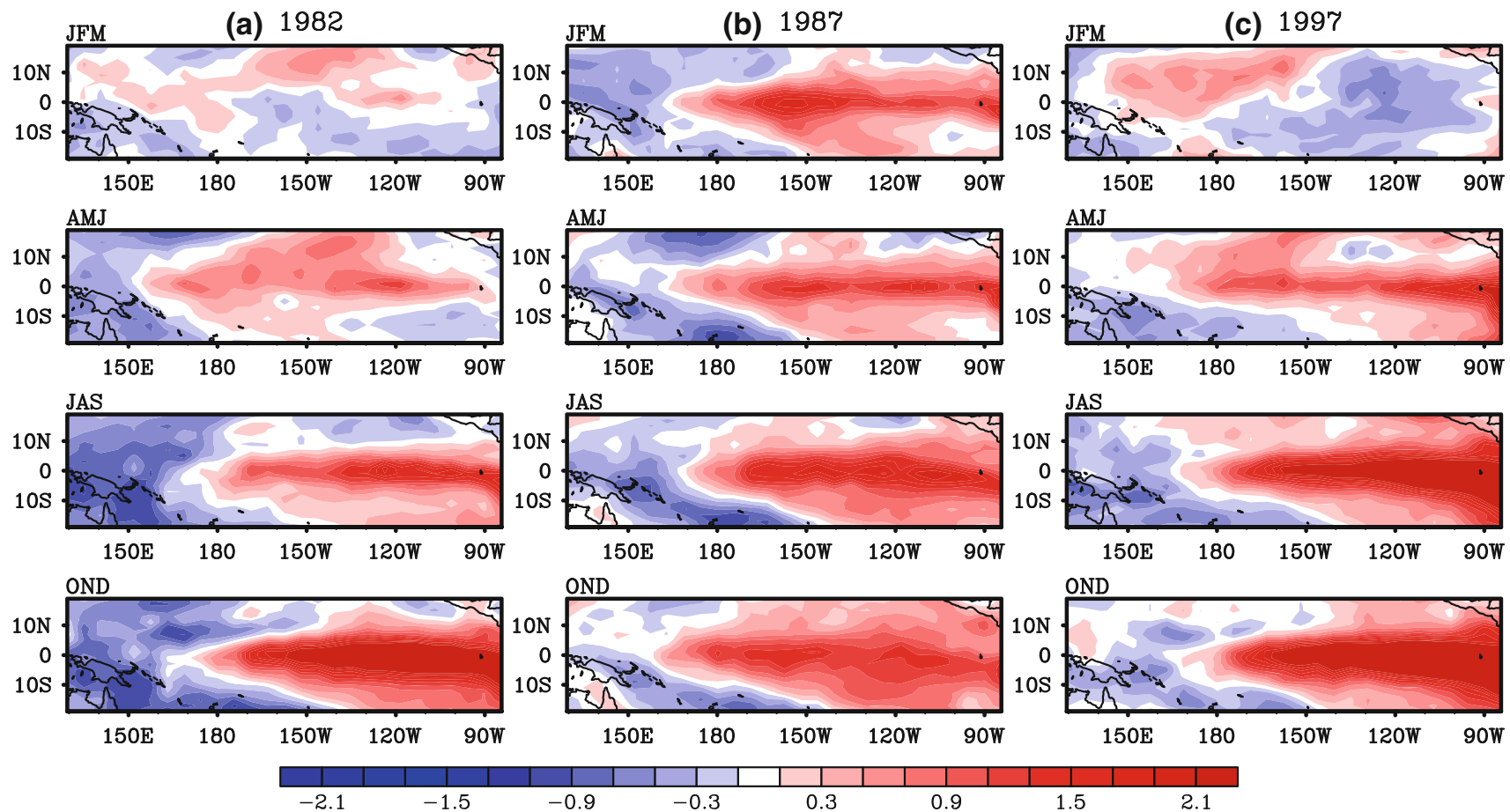

Fig. 1 The SST anomaly component of the observed EP-El Niño seasonal evolution (derived from HadISST data; units in ${ }^{\circ} \mathrm{C}$ ). The EP-El Niño events are a 1982, b 1987 and c 1997

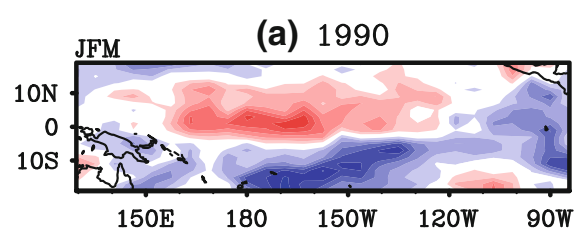

Three CP-El Nino SST Anomaly
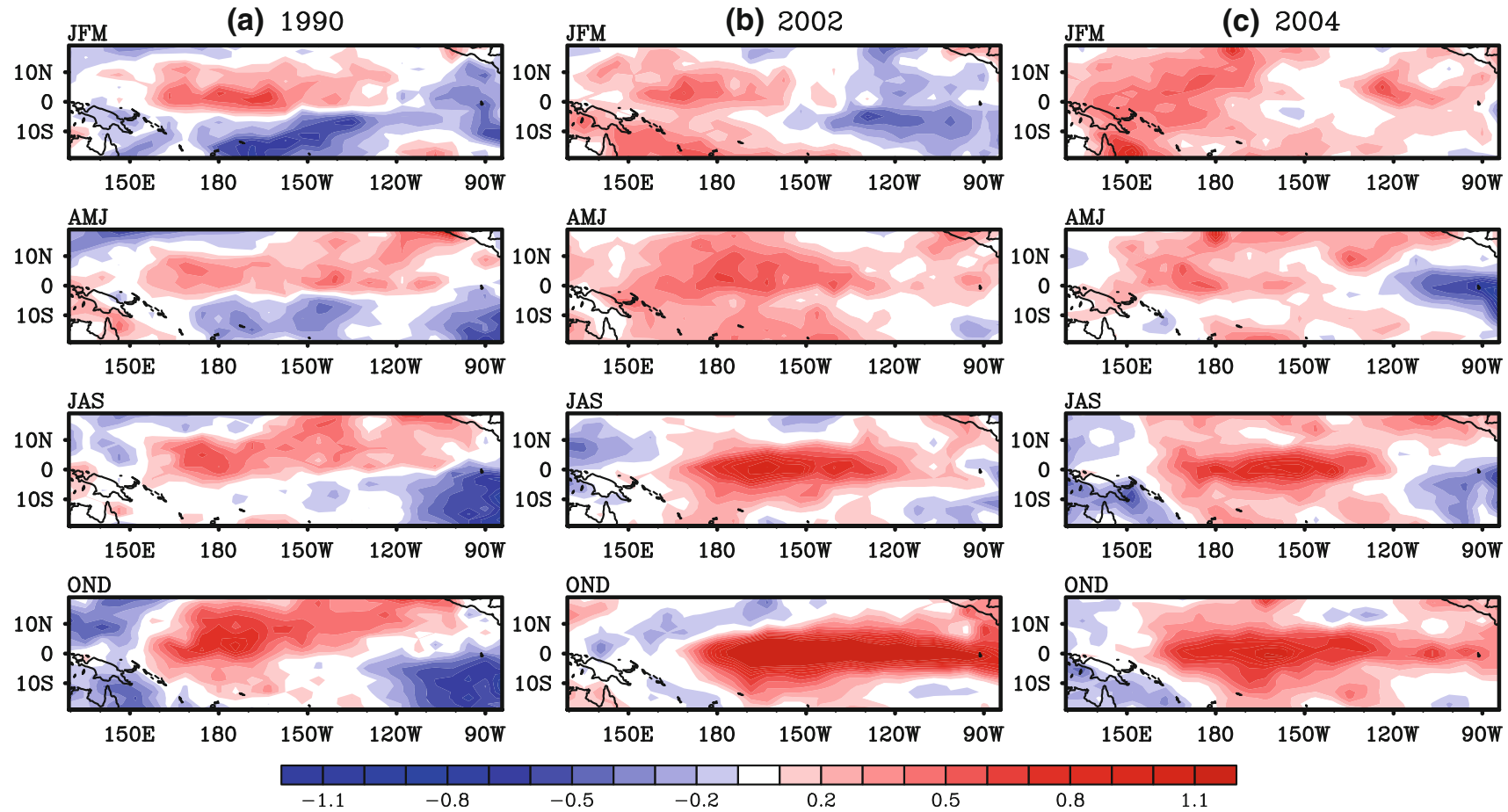

Fig. 2 The SST anomaly component of the observed CP-El Niño seasonal evolution (derived from HadISST data; units in ${ }^{\circ} \mathrm{C}$ ). The CP-El Niño events are a 1990, b 2002 and c 2004 
procedure provided by Chen et al. (1995) to yield the initial anomalies of the Zebiak-Cane model and then simulate the El Niño events. Concretely, the model was initialized in a coupled manner using a simple data procedure in which the coupled model wind stress anomalies were nudged towards the observations. The relative weight of the model wind stress anomalies versus the observations are originally derived from Chen et al. (1995). With these initial anomalous fields, we consider the external forcing of the tendency equation of the SST-equation and compute the OFV, finally superimposing the OFV to the model and attempting to make the model simulation fit the observed El Niño events.

For the time window $\left[t_{0}, t_{k}\right]$ associated with the OFV (see Sect. 2), we choose 12 months before the time of the peak phase of the El Niño events to act as the simulation time window of the observed El Niño events. That is, we try to simulate the growth of the El Niño. For example, the 1982 El Niño events had peak values in December 1982, and the simulation time window here is chosen as the period from January to December 1982; the 1987 El Niño event has a peak value in September 1987, and the simulation time window can be chosen as the period from October 1986 to September 1987. For the simulation time window, we compute one component of the OFV every month (the time step of the model integration is 10 days) with the predetermined initial anomaly fields (see last paragraph) and finally obtain the OFV with 11 components (see Sect. 2).

\subsubsection{Simulating the CP-El Niño events by the OFV approach}

We use the El Niño-related wind stress derived from the observed wind and the initialization procedure provided by Chen et al. (1995) to obtain the initial oceanic anomalies at the start time $t_{0}$ of the optimization time window $\left[t_{0}, t_{k}\right]$. With these initial anomalies, we run the Zebiak-Cane model forced by the corresponding OFVs (see Fig. 3) for one year and obtain the simulations of the three observed CP-El Niño events. In Fig. 4, we plot the simulated SST anomaly patterns for the three CP-El Niño years. It is shown that with the OFVs, the simulated warm SST anomaly occurs after the boreal spring and reaches its peak value in the boreal winter. Furthermore, we notice that the activities of the simulated CP-El Niño event tend to concentrate in the central Pacific and then extend somewhat eastward. For a comparison, we find that these characteristics of the SST anomaly evolution shown in the simulated CP-El Niño years agree very well with the observations (see Figs. 2, 4). In Table 1, we list the spatial correlations of the SST anomaly component for the observed and

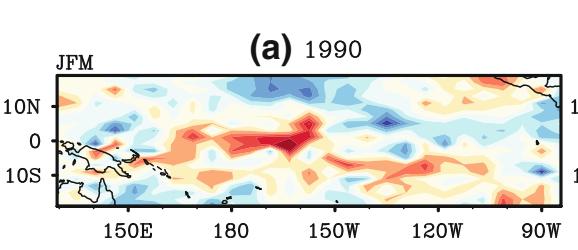

The OFVs of three CP-El Nino
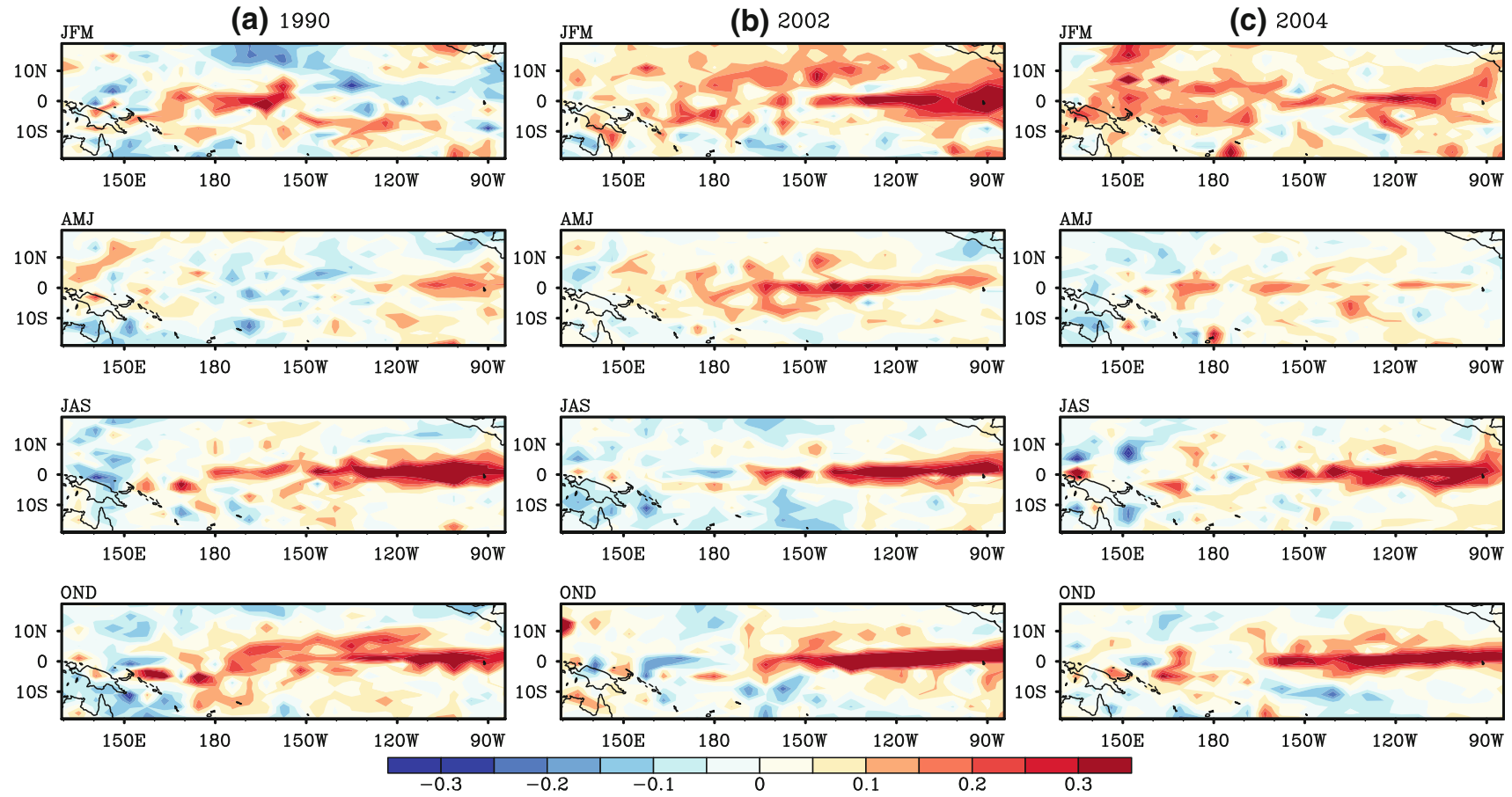

Fig. 3 The OFVs for three CP-El Niño events. For each El Niño year, one OFV includes 11 components, which correspond to 11 time intervals (one interval ranges from 1 month to the next month) of
1 year (see Sects. 2, 3). This figure shows a mean of the components in each season. a 1990 CP-El Niño year; b 2002 CP-El Niño year; c 2004 CP-El Niño year 
(a) 1990: Simulation

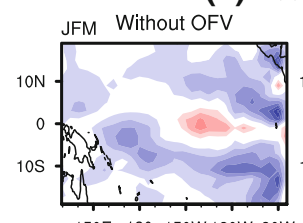

150E 180 150W 120W 90W

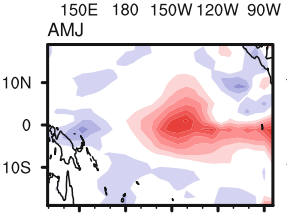

150 E 180 150W $120 \mathrm{~W}$ 90W

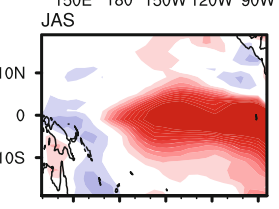

150E 180 150W 120W 90W
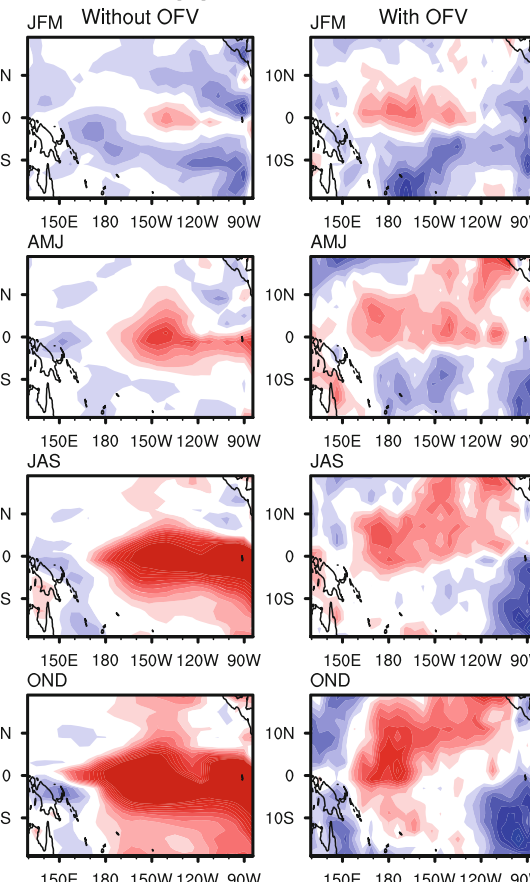

150E 180 150W 120W 90W AMJ

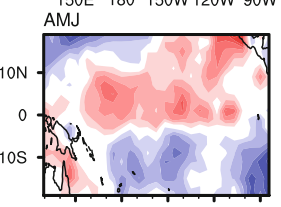

150E 180 150W 120W 90W

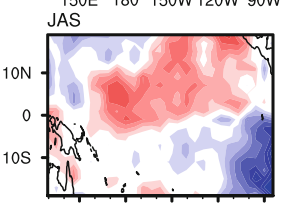

150E 180 150W 120W 90W

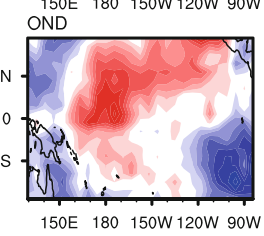

(b) 2002: Simulation

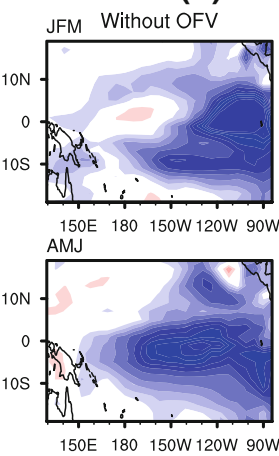

50E 180 150W $120 \mathrm{~W} 90 \mathrm{~W}$

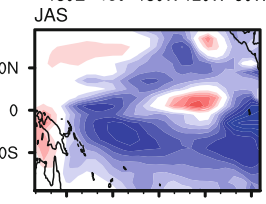

50E 180 150W 120W 90W OND

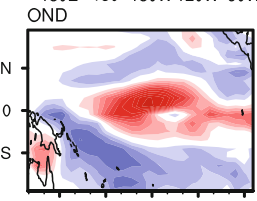

150E 180 150W 120W 90W

$-0.5$

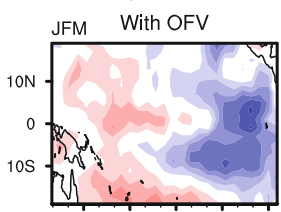

150E 180 150W $120 \mathrm{~W}$ 90W AM

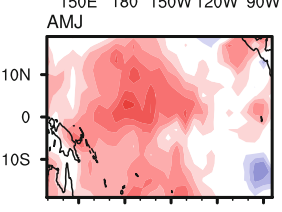

150E 180 150W 120W 90W $150 E$
JAS

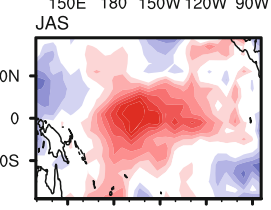

I50E 180 150W 120W 90W OND

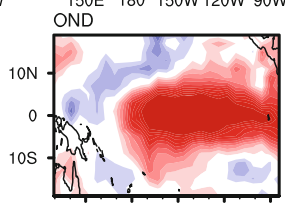

150E 180 150W 120W 90W 0.5 (c) 2004: Simulation
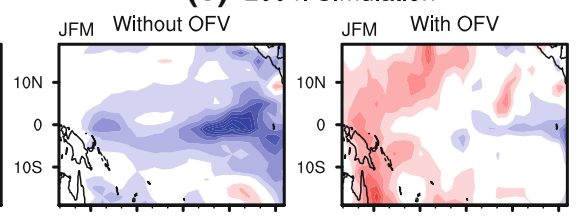

150E 180 150W 120W 90W AMJ

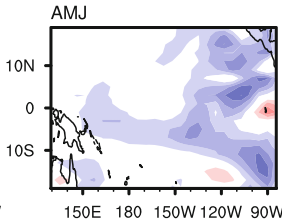

150E 180 150W 120W 90W

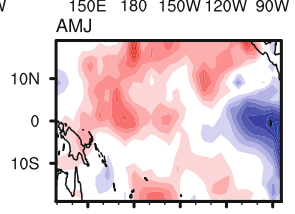

150E 180 150W 120W 90W

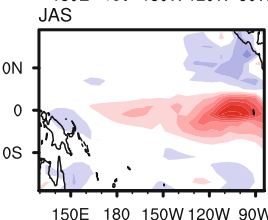

50E 180 150W 120W 90W

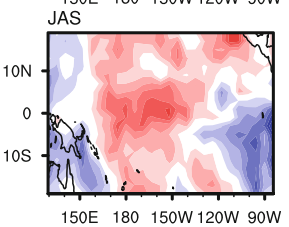

OND

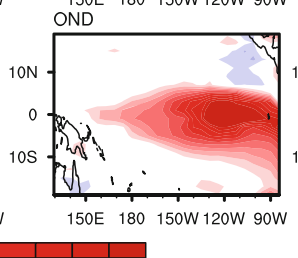

OND

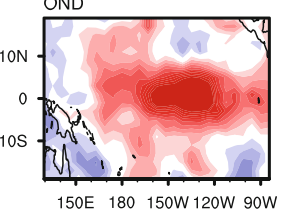

Fig. 4 The SST anomaly component of the seasonal evolutions of the a 1990, b 2002, and c 2004 CP-El Nino events simulated by the ZebiakCane model with and without the OFVs, respectively

simulated CP-El Niño years. The observed SST anomalies and the simulated anomalies with the OFV possess very high correlation coefficients in the spatial patterns and fit very well. This result indicates that the behaviors of the SST anomaly for the three observed CP-El Nino events are well traced by the Zebiak-Cane model with the corresponding OFVs.

For comparison, we do not consider the forcing of the OFVs and examine the simulation of the CP-El Niño events by running the Zebiak-Cane model with the initial anomalies generated by the Chen et al. (1995) procedure. Here, only the role of the initial field is considered. The results show that none of the three CP-El Niño events can be reproduced by the Zebiak-Cane model (Fig. 4). Actually, the Zebiak-Cane model without the OFV produces either the EP-El Niño events or the events without a warm SST signal. Furthermore, the correlation coefficients between the simulated SST anomalies and the observed anomalies are very low (see Table 1). All of these results show that the Zebiak-Cane model, if we do not consider the role of the OFV, cannot reproduce the CP-El Niño events.

We note that in CP-El Niño simulations, only the tendency of the SST-equation is corrected by the corresponding OFV to fit the observations. We then naturally ask whether other related physical variables can be corrected to agree with the observations. In other words, can
Table 1 The correlation coefficients of the observed SST anomalies with the simulated SST anomalies for three CP-El Niño years

\begin{tabular}{llllrrrl}
\hline & & Feb. & Apr. & \multicolumn{1}{l}{ June } & Aug. & Oct. & Dec. \\
\hline 1990 & OFV & 0.995 & 0.986 & 0.976 & 0.961 & 0.966 & 0.956 \\
& No-OFV & 0.052 & 0.207 & -0.058 & -0.233 & -0.215 & 0.131 \\
2002 & OFV & 0.995 & 0.972 & 0.958 & 0.958 & 0.976 & 0.976 \\
& No-OFV & 0.556 & 0.400 & -0.137 & -0.108 & 0.405 & 0.720 \\
2004 & OFV & 0.995 & 0.972 & 0.976 & 0.902 & 0.835 & 0.805 \\
& No-OFV & 0.176 & 0.153 & -0.066 & -0.042 & 0.301 & 0.475
\end{tabular}

'OFV' ('No-OFV') denotes the correlation coefficient of the with(without-) OFV-simulated SST anomalies with the observed anomalies. All results simulated with the OFV are statistically significant at the $99 \%$ level

the Zebiak-Cane model with the OFV describe the physical feedback of the different physical variables associated with CP-El Niño events?

To address this question, we plot the simulated zonal wind (Fig. 5) and thermocline depth anomalies (Fig. 6) associated with the CP-El Niño events. For the simulation of CP-El Niño events generated by the Zebiak-Cane model with the OFV, westerly wind anomalies often occur in the equatorial and off-equatorial western Pacific; also, during the mature phase, westerly wind anomalies still occur in the western Pacific but easterly wind anomalies 

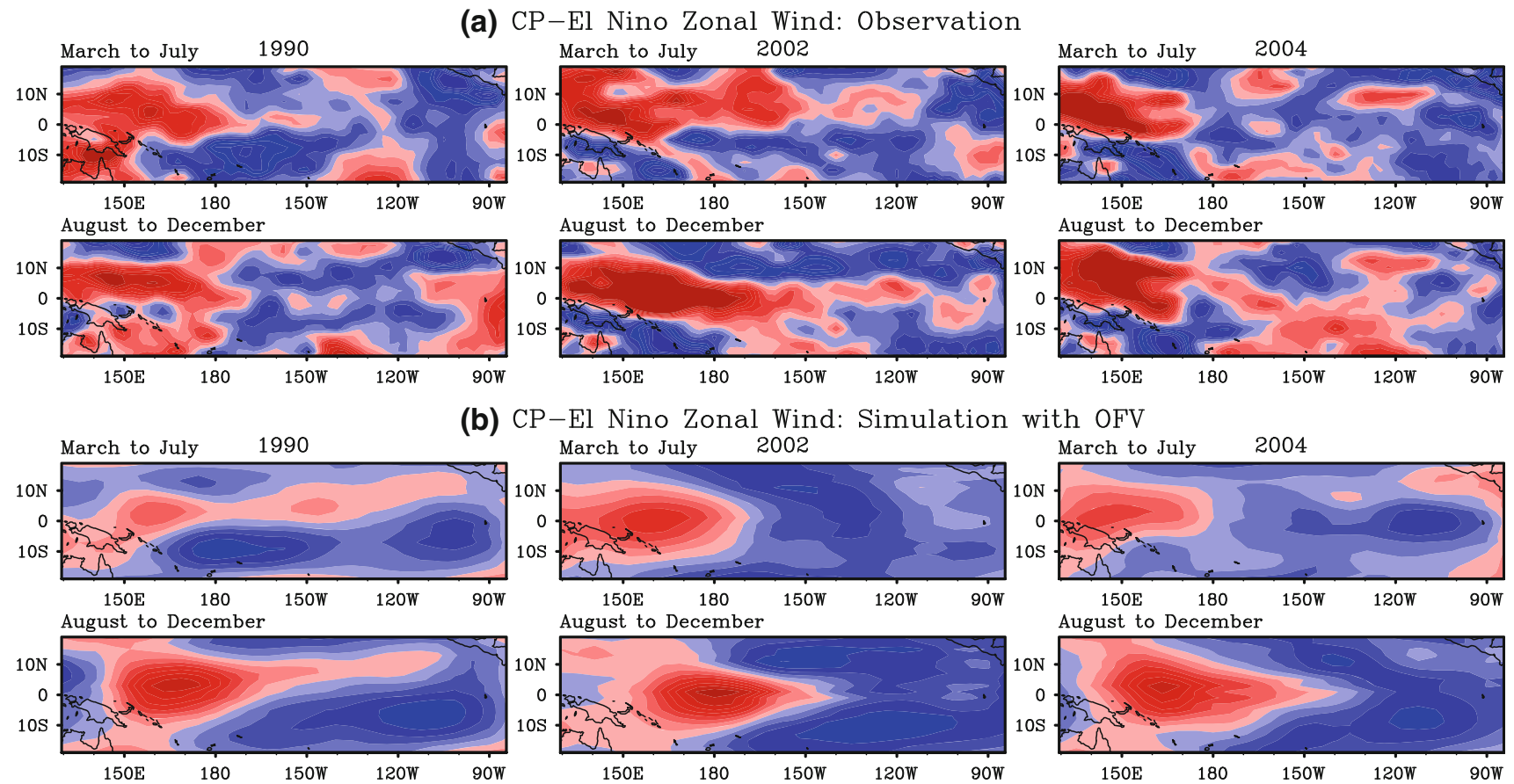

(c) $\mathrm{CP}-\mathrm{El}$ Nino Zonal Wind: Simulation without OFV
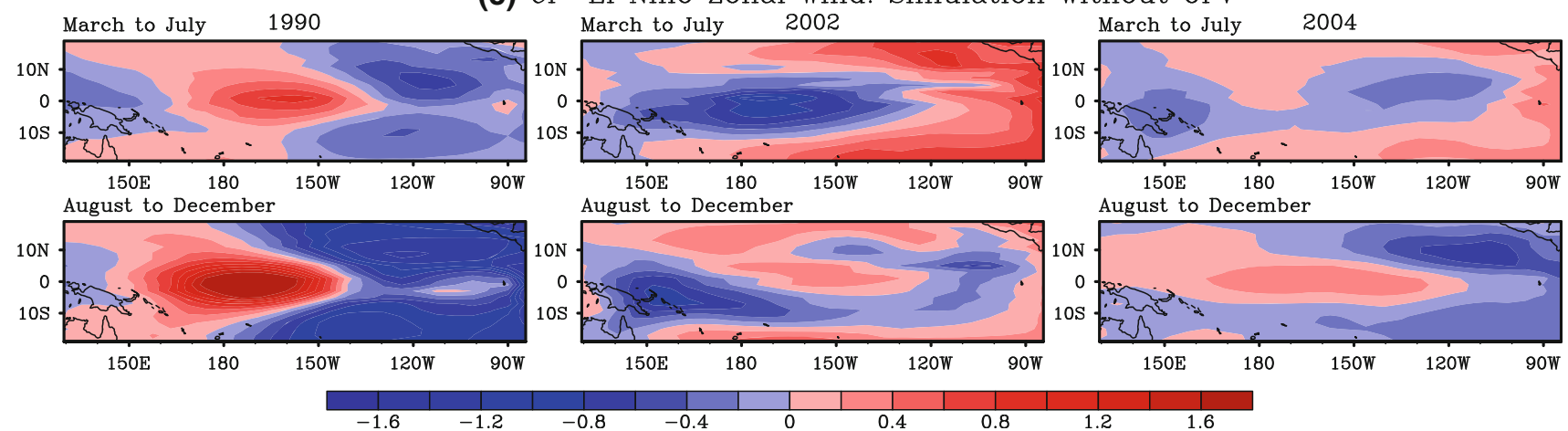

Fig. 5 The Zonal wind anomalies (units in $\mathrm{m} / \mathrm{s}$ ) for three CP-El Niño events. The anomalies in each case are averaged from March to July and from August to December. a Observed zonal wind, derived from the NCEP/NCAR reanalysis data; b simulated zonal wind with OFV; and $\mathbf{c}$ simulated zonal wind without $\mathrm{OFV}$

depth anomalies are also concentrated in the central Pacific, the maximum values occur on both sides of the equator instead of directly on the equator. Despite such differences, the SST anomaly components of the three CP-El Nino events are still well reproduced by the Zebiak-Cane model with the corresponding OFV. We therefore conclude that subsurface ocean feedback may have little impact on CP-El Niño evolution. In fact, Yu and Kim (2010) demonstrated that CP-El Niño events involve only a shallow layer of subsurface ocean temperature variations and are less related to the thermocline variations (also see Kug et al. 2009; Kao and Yu 2009). Furthermore, Kug et al. (2009) and Kao and $\mathrm{Yu}$ (2009) demonstrated that the CP-El Nino events tend to be more influenced by the zonal advection and heat flux variations. All of these results may explain why the 
(a) CP-El Nino Thermocline Depth: Observation
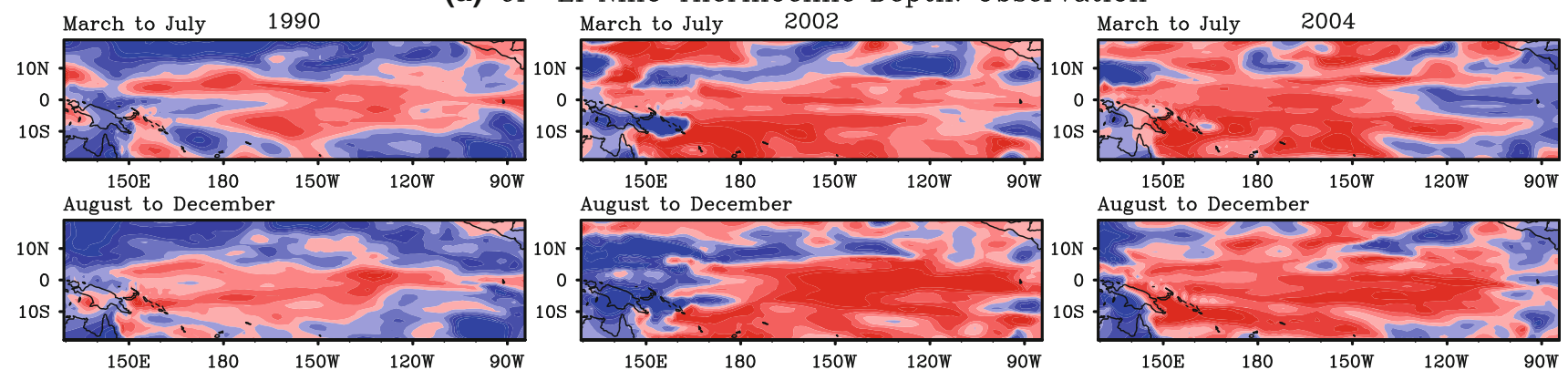

(b) CP-El Nino Thermocline Depth: Simulation with OFV
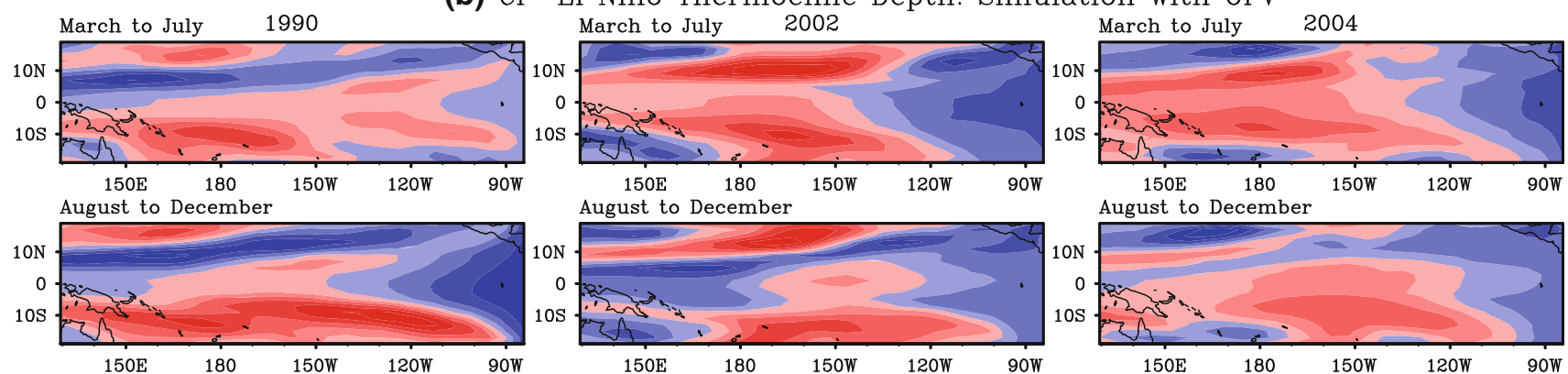

(c) CP-El Nino Thermocline Depth: Simulation without OFV
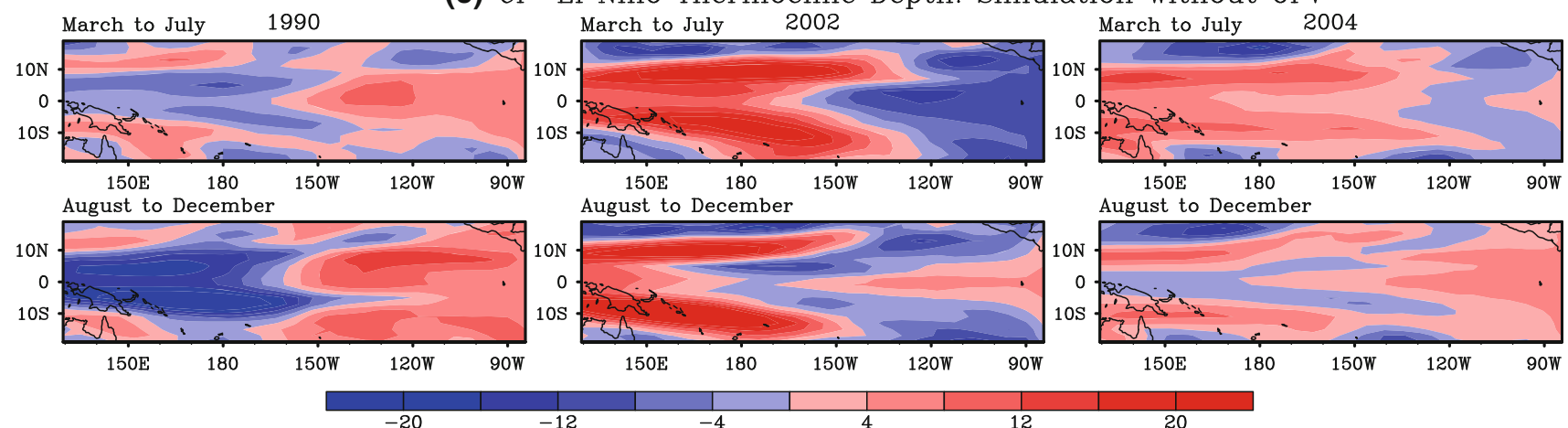

Fig. 6 Same as Fig. 5, but for thermocline depth anomalies (units in m). The observations are from the EMC/CMB data

Zebiak-Cane model with the corresponding OFV fails to describe the thermocline depth variation but reproduces the SSTA component of the CP-El Nino events well. These results also reveal that the model with the OFV depicts the role of zonal wind variation in the occurrences of $\mathrm{CP}-\mathrm{El}$ Nino events.

In summary, we have demonstrated that the behavior of the SSTA as well as the CP-El Niño wind fields can be reproduced by the Zebiak-Cane model with the OFVs. Furthermore, the thermocline depth simulations lead us to believe that the discharge process of the equatorial heat content associated with the CP-El Niño is not efficient and emphasizes the role of the zonal advection in the development of CP-El Nino events, as found by previous studies. Therefore, the CP-El Niño simulation is acceptable, where the OFV plays an important role in correcting the air-sea interaction described by the Zebiak-Cane model.

\subsubsection{Simulating the EP-El Niño events by the OFV approach}

In this section, we attempt to simulate the EP-El Niño events using the Zebiak-Cane model. For the 1982, 1987, and 1997 EP-El Niño events, we use the initial anomalies generated by the procedure presented by Chen et al. (1995) and integrate the Zebiak-Cane model for 12 months with the given start month (see Sect. 3.2). In Fig. 7, we plot the seasonal SSTA of the three resultant events. The 1982 and 1987 El Niño events are roughly reproduced, but the simulated 1997 El Niño event tends to exhibit a decaying El Niño-like event. That is to say, the observed 1997 El Niño is not captured by the Zebiak-Cane model with the initialization procedure of Chen et al. (1995) (for the reason, some discussions are presented in Sect. 3.2.3). However, when we apply the OFV (see Fig. 8) to the Zebiak-Cane 
Simulations of three EP-El Nino without OFV
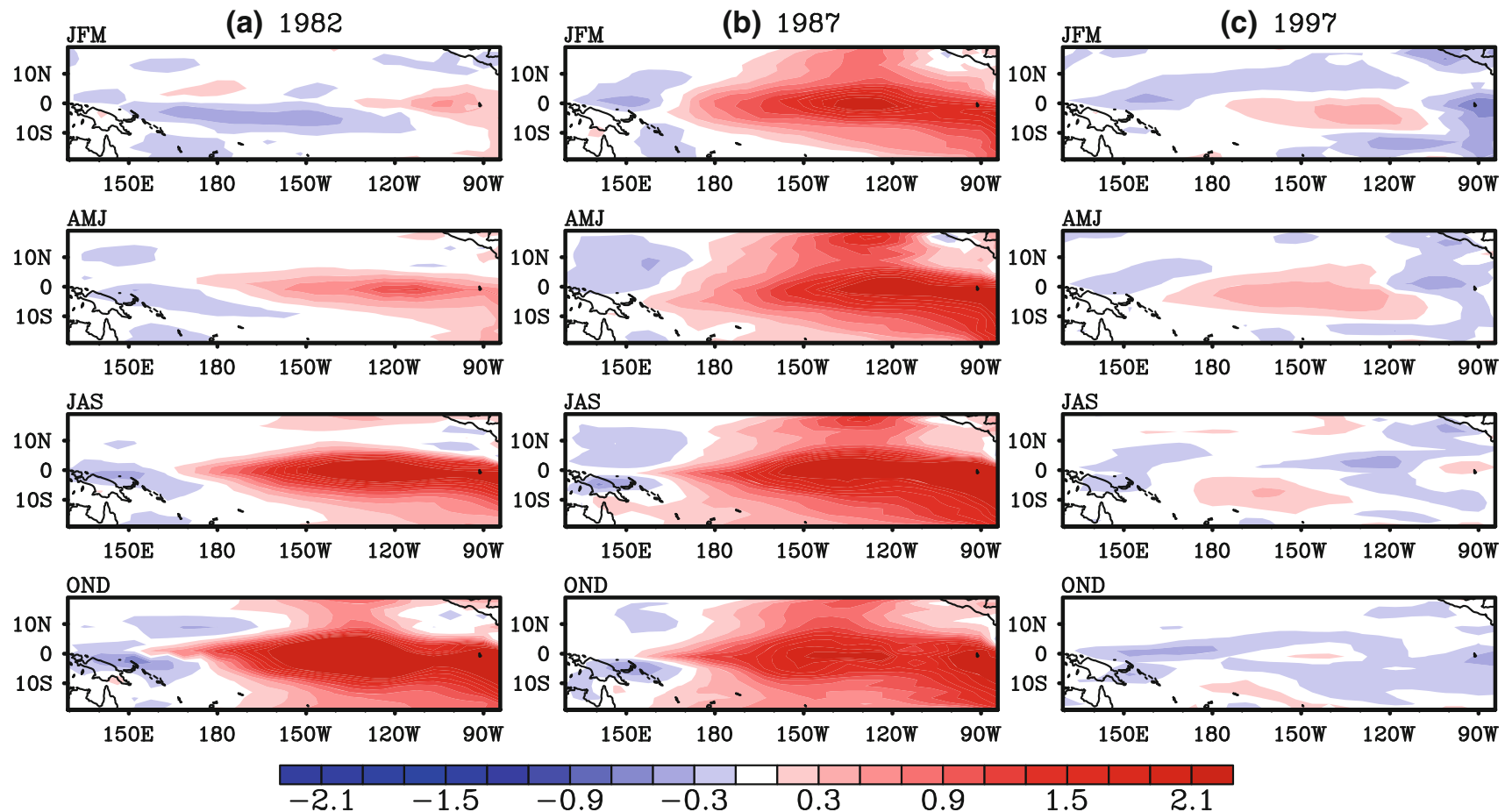

Fig. 7 The SST anomaly component of the seasonal evolutions of the a 1982, b 1987, and c 1997 EP-El Nino events simulated by the ZebiakCane model without the OFVs

model, the $1997 \mathrm{El}$ Niño is well reproduced by the ZebiakCane model (see Fig. 9); furthermore, the 1982 and 1987 El Niño events are much better reproduced (see Table 2). The other physical variables, such as thermocline depth anomaly and zonal wind field, also agree very well with the observation (Figs. 10, 11). In fact, the anomalous zonal westerly shown in Fig. 10 shows a clear eastward propagation from the western Pacific, covering a large part of the tropical Pacific, with the wind converging into the eastern Pacific indicating a slackening of the tropical trade winds as well as Walker circulation followed by a weakened upwelling of cold water in the tropical eastern Pacific. The weakened upwelling suppresses the SSTA cooling and favors a warm SST occurrence in the equatorial eastern Pacific. On the other hand, the anomalous zonal westerly generates an anomalous oceanic state in the tropical Pacific Ocean. Figure 11 shows the variations of the subsurface water temperature associated with the thermocline. The subsurface water becomes warming in the equatorial eastern Pacific but cooling in the equatorial western Pacific. This result indicates that the related thermocline is deepening over the equatorial eastern Pacific but is shoaling over the equatorial western Pacific. The deepening thermocline over the equatorial eastern Pacific induces a strong warm vertical advection by a mean upwelling in the eastern Pacific (Kang et al. 2001; An and Jin 2001) and also helps warm the SST in the eastern Pacific. All of these atmospheric and oceanic conditions enhance the likelihood of an El Nino event. The thermocline depth feedback associated with vertical advection is clearly a key process for EP-El Nino occurrences (also see Jin 1997), which may be different from CP-El Niño events.

\subsubsection{Relative importance of initial error and model error in yielding simulation uncertainties of observed EP- and CP-El Nino}

The above results are derived from the initialization procedure suggested by Chen et al. (1995). In numerical experiments, we also adopt another initialization procedure based on a variational data assimilation, which yields the optimal initial condition of the model and makes the model output in the future time closest to the observation.

For the CP-El Nino events, results from the two initialization procedures are similar. That is, the Zebiak-Cane model with the OFVs reproduces the three CP-El Nino events while that without the OFV fails to depict the CP-El Nino events. It is indicated that severe model errors exist in the Zebiak-Cane model for modeling the CP-El Niño events and the OFVs can offset the model errors and allow the Zebiak-Cane model to reproduce the $\mathrm{CP}-\mathrm{El}$ Nino events well.

For the EP-El Nino events, the results from the initialization procedure of the variational data assimilation are a bit different from those obtained by the initialization 
The OFVs of three EP-El Nino
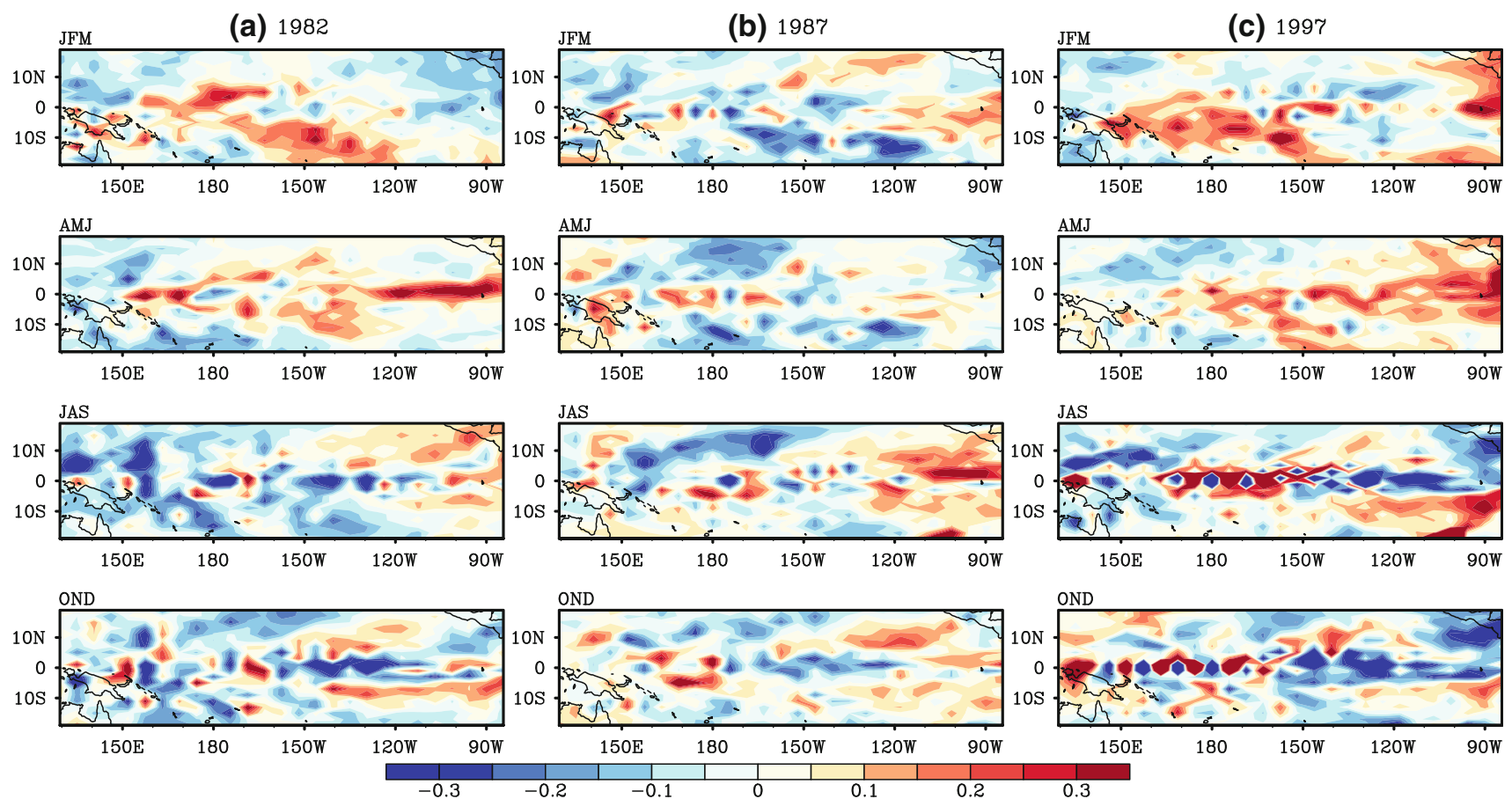

Fig. 8 Same as Fig. 3, but for three EP-El Niño events: a 1982 EP-El Nino year; b 1987 EP-El Nino year; c 1997 EP-El Nino year

Fig. 9 The SST anomaly component of the seasonal evolution for the 1997 El Nino simulated by the Zebiak-Cane model. a The simulation without OFV, b the simulation with OFV
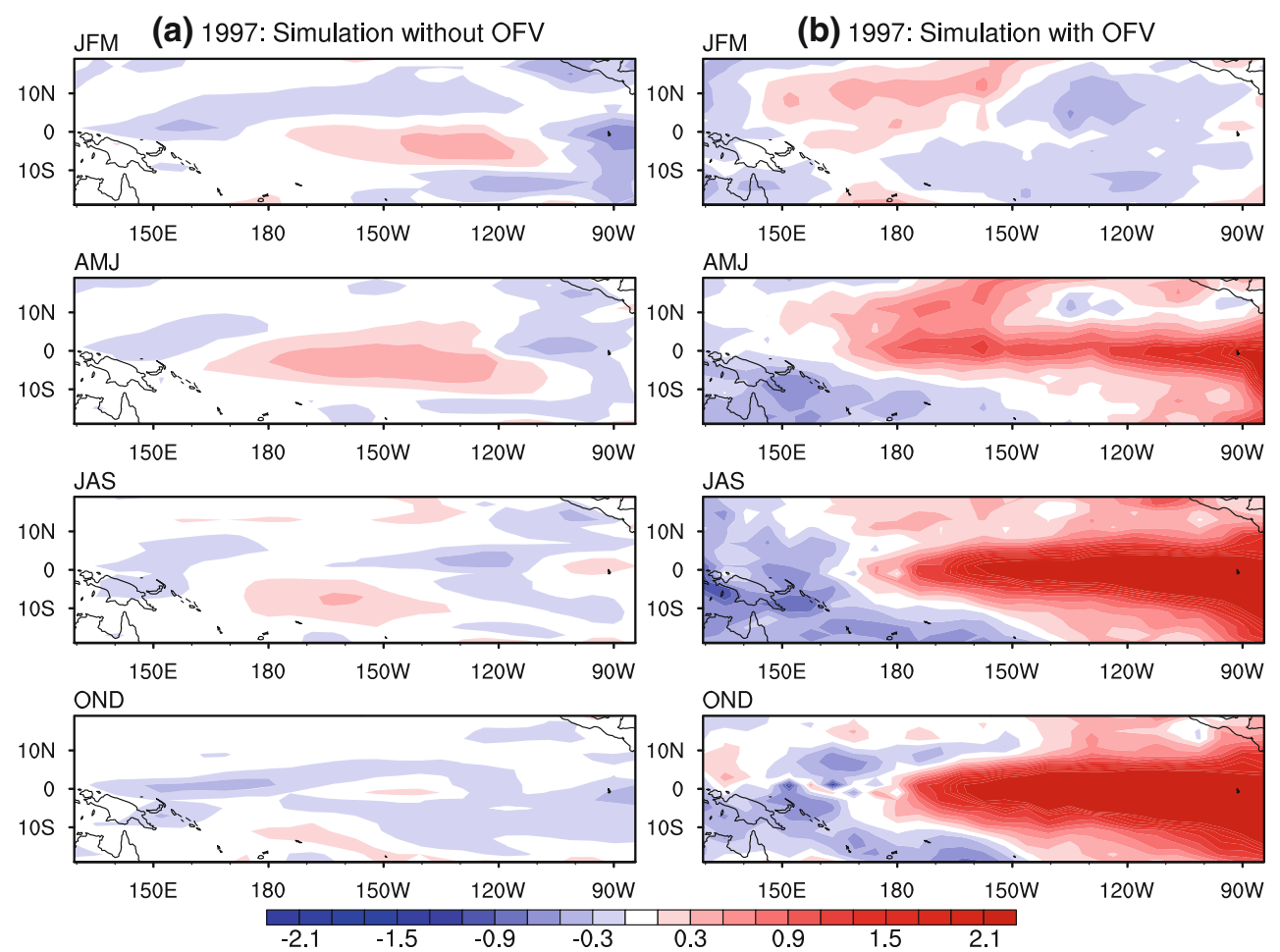

procedure of Chen et al. (1995). In the case of the initialization procedure of Chen et al. (1995), we have shown that the Zebiak-Cane model without the OFV approximates the 1982 and 1987 El Niño events but fails to produce the 1997
El Nino event; however, for the initialization procedure of the variational data assimilation, the model without the OFV produces all these three El Nino events (see Fig. 12 for the 1997 El Nino simulation). That is to say, with a 
Table 2 The correlation coefficients of the observed SST anomalies with the simulated SST anomalies for three EP-El Niño years

\begin{tabular}{rlllllrr}
\hline & & Feb. & Apr. & June & Aug. & Oct. & Dec. \\
\hline 1982 & OFV & 0.998 & 0.997 & 0.994 & 0.995 & 0.996 & 0.998 \\
1987 & No-OFV & 0.141 & 0.001 & 0.649 & 0.836 & 0.883 & 0.867 \\
& OFV & 0.992 & 0.984 & 0.972 & 0.954 & 0.883 & 0.825 \\
1997 & No-OFV & 0.794 & 0.725 & 0.649 & 0.776 & 0.790 & 0.649 \\
& OFV & 0.997 & 0.991 & 0.994 & 0.993 & 0.990 & 0.994 \\
& No-OFV & -0.173 & 0.036 & 0.023 & -0.132 & -0.384 \\
\hline
\end{tabular}

'OFV' ('No-OFV') denotes the correlation coefficient of the with- (without-) OFV-simulated SST anomalies with the observed anomalies. All results simulated with the OFV are statistically significant at the $99 \%$ level

(a) EP-El Nino Zonal Wind: Observation
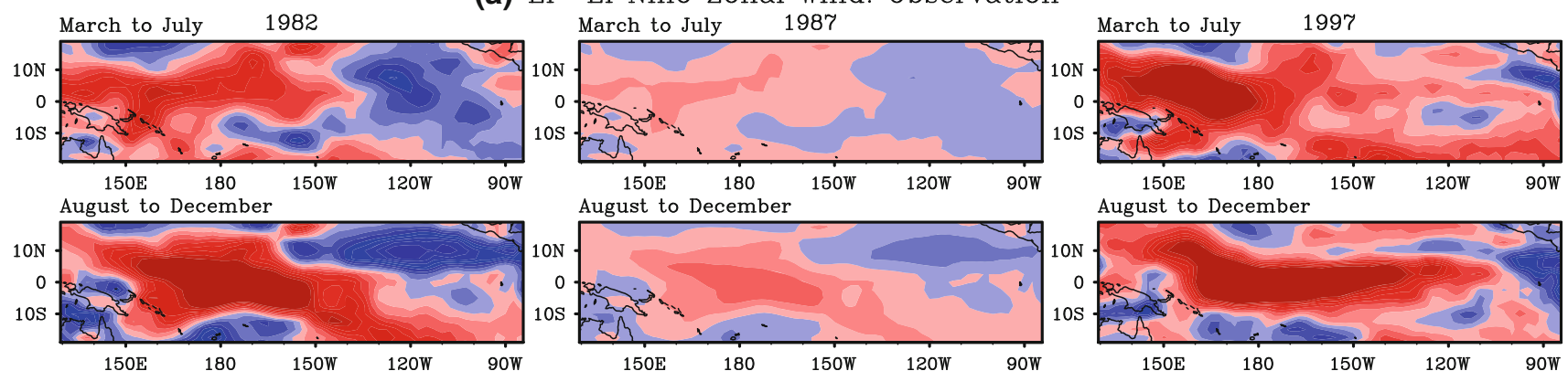

(b) EP-El Nino Zonal Wind: Simulation with OFV
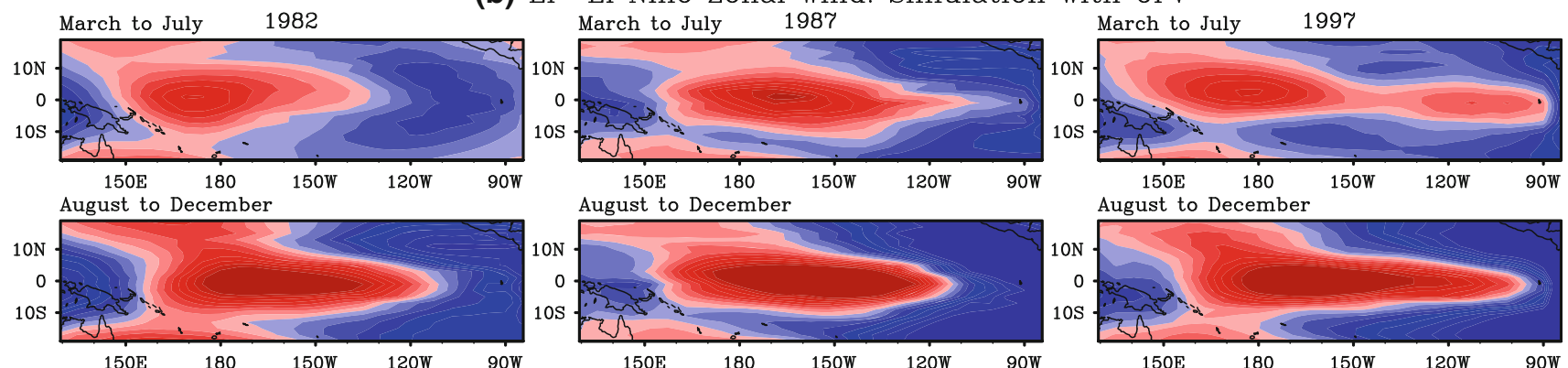

(c) EP-El Nino Zonal Wind: Simulation without OFV
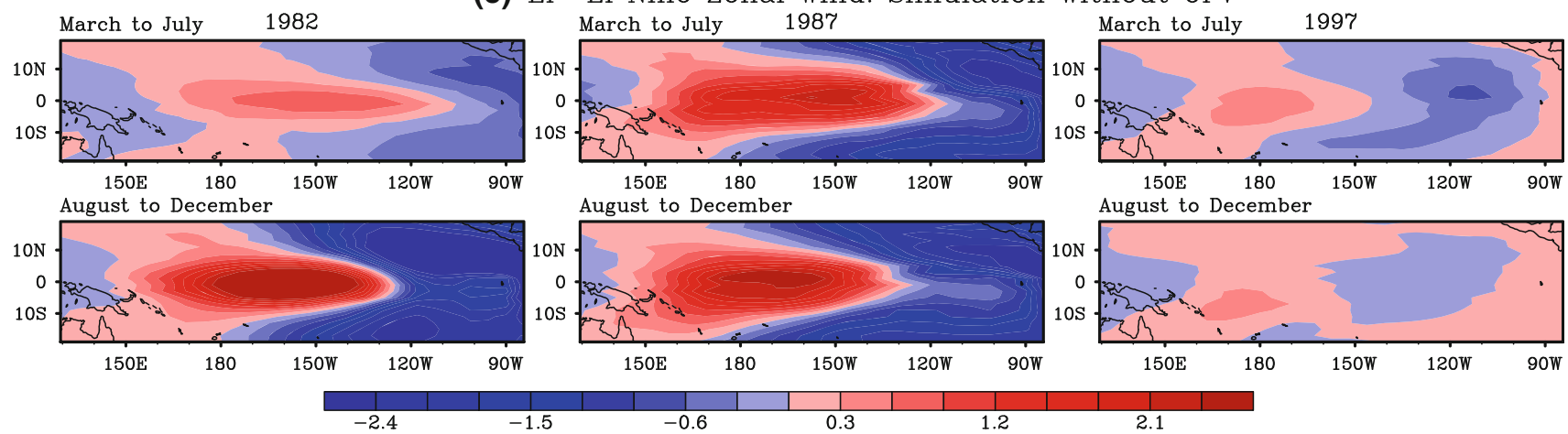

Fig. 10 The zonal wind anomalies (units in $\mathrm{m} / \mathrm{s}$ ) for three EP-El Niño events. The anomalies in each case are averaged from March to July and from August to December. a Observed zonal wind, derived

proper initial condition, the Zebiak-Cane model has the potential for reproducing the EP-El Nino events. In any case, when using the OFV, the three EP-El Nino events, as from the NCEP/NCAR reanalysis data; $\mathbf{b}$ simulated zonal wind with $\mathrm{OFV}$; and $\mathbf{c}$ simulated zonal wind without $\mathrm{OFV}$

expected, are much better simulated; in particular, the 1997 El Nino event is well reproduced even in the case of initialization procedure of Chen et al. (1995). These imply 
(a) EP-El Nino Thermocline Depth: Observation
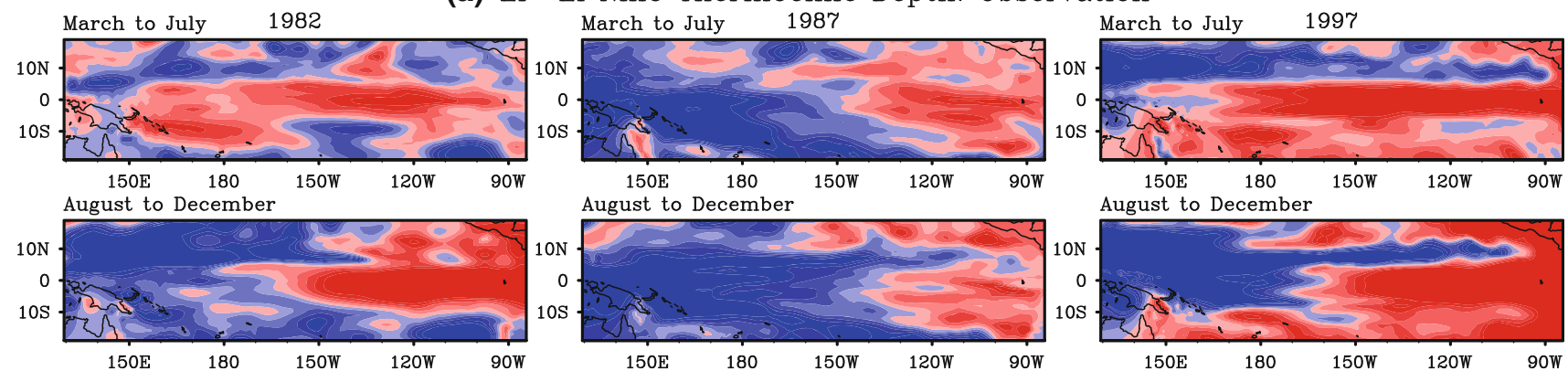

(b) EP-El Nino Thermocline Depth: Simulation with OFV
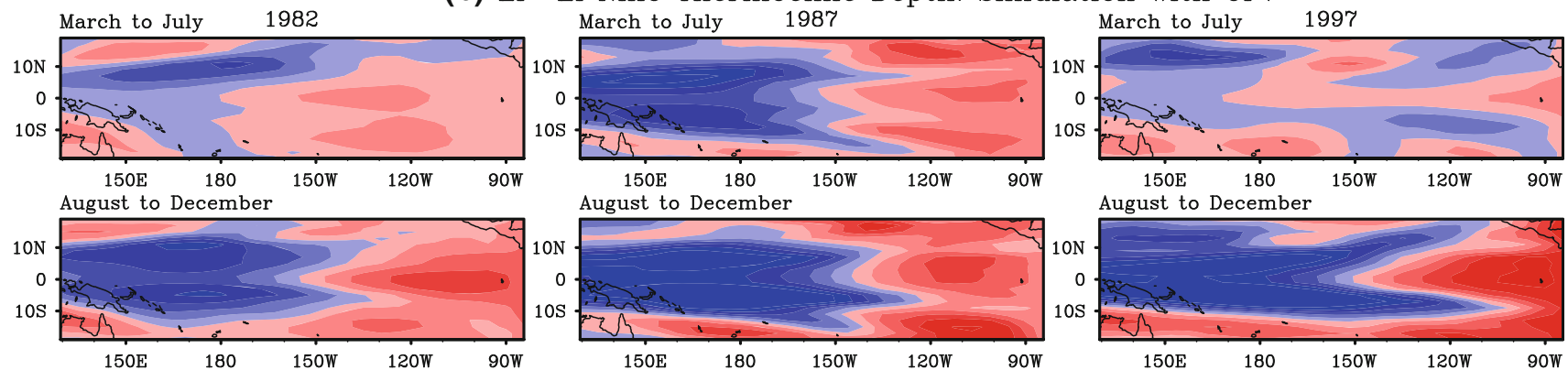

(c) EP-El Nino Thermocline Depth: Simulation without OFV
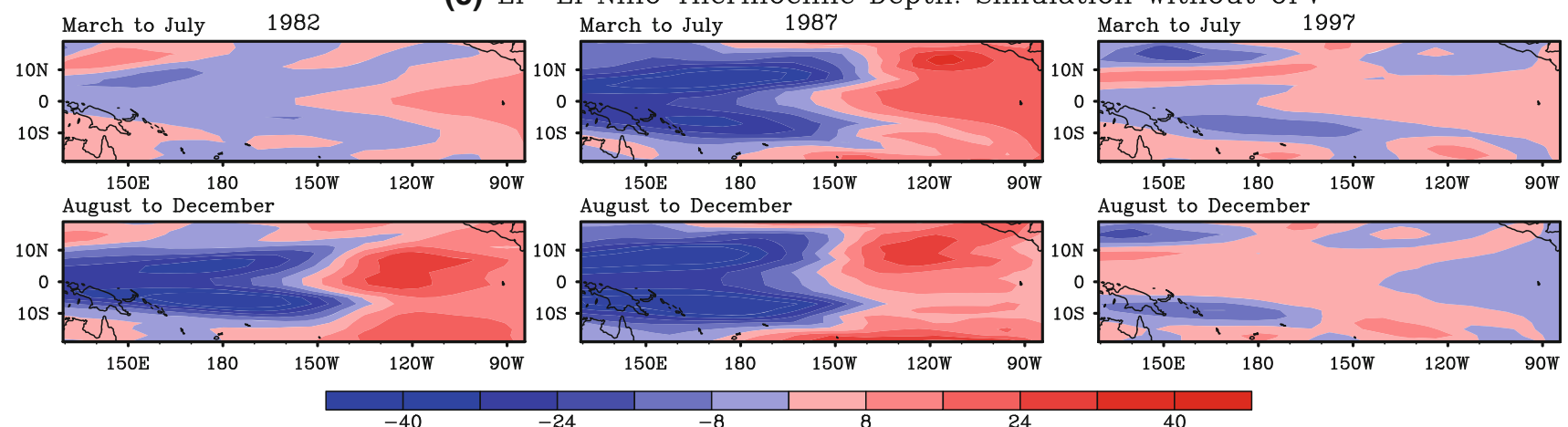

Fig. 11 Same as Fig. 10, but for the thermocline depth anomaly (units in $\mathrm{m}$ ). The observations are from the EMC/CMB data

that a proper initial field plays a key role in reproducing EP-El Nino events and small amplitudes of model errors exist in the Zebiak-Cane model for modeling EP-El Nino events.

From the simulations of the 1997 El Nino event with both initialization procedures, it is inferred that the OFV can correct not only the model errors caused by tendency errors but also the analysis errors caused by the initial uncertainties. Comparison between the simulations with the OFV and without the OFV (or between the simulations with the two initialization procedures) demonstrates that strong westerly wind burst (WWB) event in spring plays an important role in the onset of the $1997 \mathrm{El} \mathrm{Nino} \mathrm{event.} \mathrm{After}$ the OFV or the initialization of variational data assimilation is applied to the Zebiak-Cane model for the $1997 \mathrm{El}$ Nino simulation, the WWB event is enhanced (see Fig. 13), which is much favorable for warming the equatorial central and eastern Pacific SST through combined effects of surface advection and downwelling Kelvin waves, leading to a strong EP-El Nino event.

When compared with the CP-El Niño simulations generated by the Zebiak-Cane model either with or without the OFV, the EP-El Niño events are often much better simulated than the CP-El Nino events. This may indicate that the present Zebiak-Cane model is good at simulating the EP-El Niño events but not at simulating the CP-El Niño events. The Zebiak-Cane model may also be better at forecasting EP-El Nino events.

\section{Implications}

We have demonstrated that the Zebiak-Cane model exists severe model errors in simulating the CP-El Nino events 
Fig. 12 The SST anomaly component of the seasonal evolution of the 1997 El Nino simulated by the Zebiak-Cane model with a the initialization procedure presented by Chen et al. (1995) and b the initialization procedure of the variational data assimilation
Fig. 13 The differences in zonal wind anomaly between the simulations with and without the OFV. After the OFV is applied to the model, the westerly wind burst event is enhanced, which is much favorable for warming the equatorial central and eastern Pacific SST through combined effects of surface advection and downwelling Kelvin waves, leading to a strong EP-El Nino event (a)
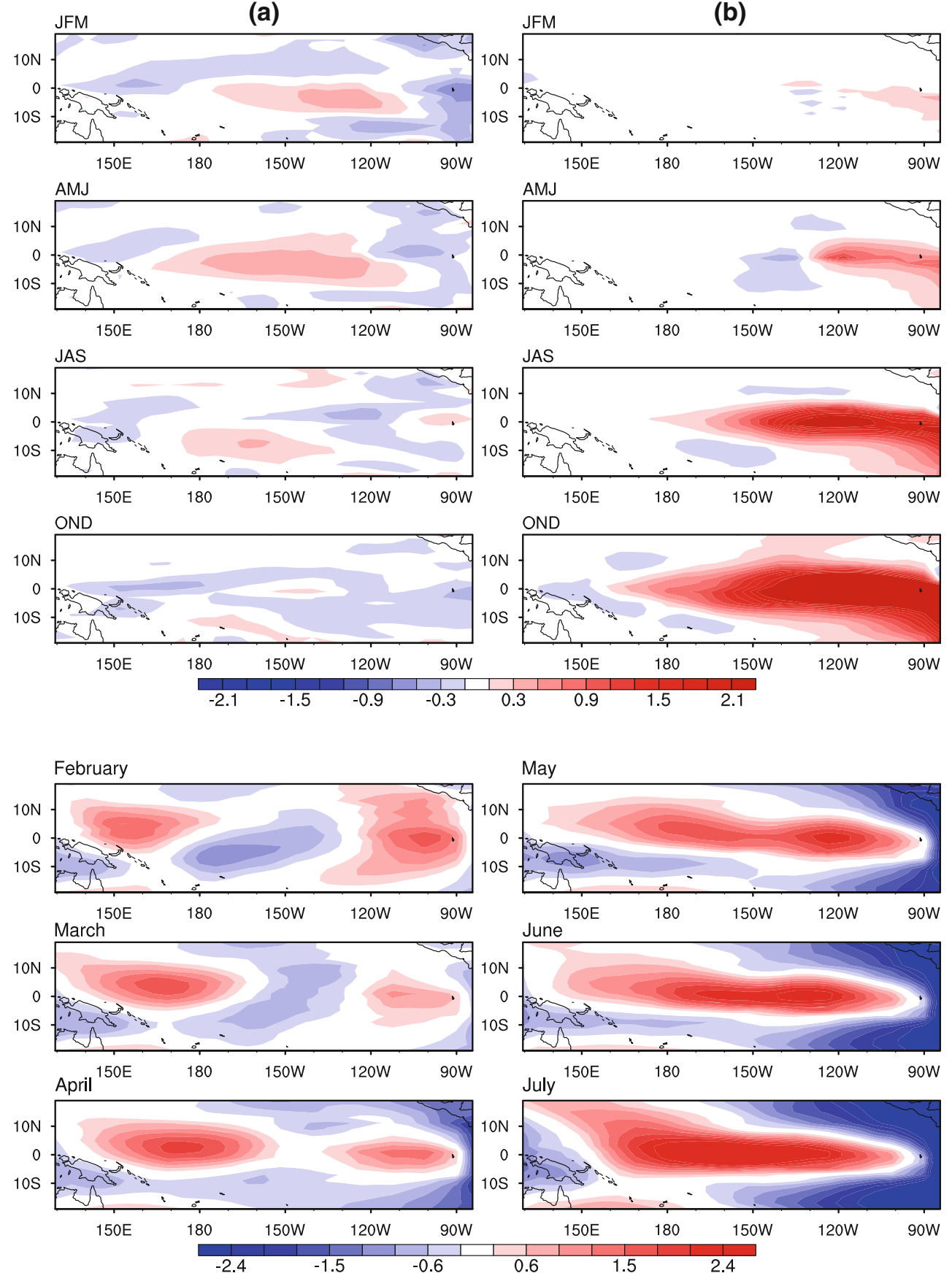

and finally fails to describe the behaviors of the CP-El Niño events. As expected, when we apply the OFV to reduce the effect of model errors, the model reproduces the observed CP-El Niño events well; thus, the OFV clearly plays an important role in offsetting model errors. The OFV associated with the three CP-El Niño events often exhibit an SSTA tendency pattern with large anomalies in the equatorial eastern Pacific (see Fig. 3); therefore, the SST tendency errors occurring in the equatorial eastern Pacific may dominate the uncertainties of the Zebiak-Cane model.
Model bias is generally caused by tendency errors. And the OFV can offset the model bias. We then naturally ask: what model bias is offset by the OFVs? To address this question, we investigate the SST differences between the CP-El Nino events simulated by the Zebiak-Cane model with the OFV (an approximation to the observation; see Table 1) and those without the OFV.

In Fig. 14, we plot a composite of the SST differences as well as the zonal wind differences for the 36 months associated with the growth phase of the three CP-El Nino events; this figure may describe the "climatological" 


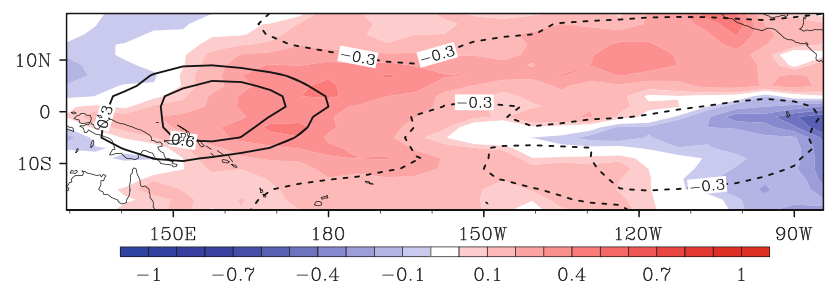

Fig. 14 The differences in the SST anomaly field (shaded) and the differences in zonal wind anomaly field (black contours) between the model simulations with and without the OFV (the former minus the latter). The growth-phase periods of three CP-El Nino years, a total of 36 months, are considered

differences between model simulations with OFV and without OFV and provide the "climatological" SST and zonal wind patterns that cannot be described by the Zebiak-Cane model. In fact, their opposite patterns present the SSTA and zonal wind components of the model bias that is offset by the OFVs. The "climatological" differences are shown to present a seesaw SST pattern with positive anomalies in the equatorial central Pacific and negative anomalies in the equatorial eastern Pacific and a zonal wind anomaly pattern with the easterly in the equatorial eastern Pacific and the westerly in the central Pacific. We demonstrate that with the OFV in the Zebiak-Cane model and the model bias being offset, the model reproduces the CP-El Nino events well; otherwise, the model tends to yield EP-El Nino events. It is implied that the CPEl Nino occurrences may be related to the seesaw SST and zonal wind patterns of the "climatological" differences. In the observations, the CP-El Nino events frequently occurred during recent decades, especially after 1990s. Does the tropical SST before and after the 1990s tend to exhibit the seesaw SST pattern? Some studies have shown similar SST trends using observed data (Zhang et al. 2010, 2011; Karnauskas et al. 2009). For example, Zhang et al. (2010) used multiple datasets to study the SST trends during the 1980-2007 period and showed an SST cold-tongue cooling mode like the seesaw SST pattern shown here (also see Zhang et al. 2011). Therefore, we guess that the SST coldtongue mode (also the seesaw SST pattern shown in this paper) may be associated with the climatological conditions of the frequent CP-El Nino occurrences.

In order to examine the role of SST cold-tongue mode in the frequent CP-El Nino occurrences, we conduct a group of sensitivity experiments, in which the SST cold-tongue mode and the related wind fields are superimposed to the climatological mean state of the Zebiak-Cane model and a modified climatological mean state is formed of the Zebiak-Cane model. With the given initialization procedures, the Zebiak-Cane model with modified climatological mean state is integrated. The results demonstrate that the El Nino events simulated by the Zebiak-Cane model with modified climatological mean state present their SST patterns with warming center departing from the east coast but still far away from the dateline. Despite such SST patterns are different from those of CP-El Nino events, the warming SST have moved westward, which may suggest the role of SST cold-tongue mode and associated wind fields. This indicates that the model bias offset by the OFV may not be only the SST cold-tongue mode and the related wind. Some studies showed that wind forcing from the subtropical and extratropical atmosphere may also play an important role in the occurrence of CP-El Nino events (e.g. Kao and Yu 2009; Yu and Kim 2011). The effect of the subtropical and extratropical atmosphere on tropical Pacific may also be absent in the Zebiak-Cane model and also be offset by the OFV. However, due to the limitation of the Zebiak-Cane model, we cannot identify the model bias induced by effect of subtropical and extratropical wind forcing. In any case, from the above discussion it is implied that the SST coldtongue mode and corresponding wind identified by the OFV could be one of the conditions for the frequent CP-El Nino events occurrences. In fact, as shown in Fig. 14, the climatological SST warming occurring in the equatorial central Pacific and the SST cooling in the equatorial eastern Pacific shown in the SST cold-tongue mode tend to increase the zonal SST gradient and enhance the easterlies in the tropical eastern Pacific and westerlies in the tropical western Pacific. The increased climatological zonal SST gradient and its accompanied westerlies in the tropical western Pacific will enhance downwelling Kelvin waves and eastward advection of warming SST in tropical western Pacific. However, the increased climatological easterlies in the tropical eastern Pacific favor westward zonal advection of cooling SST and are related to upwelling Kelvin waves, which hinder the eastward warming SST advection and suppress the eastward downwelling Kelvin waves, finally leading to the warming SST occurring in the equatorial central Pacific and favoring the occurrences of CP-El Niño events.

\section{Conclusion and discussion}

In this paper, we propose an OFV approach to offset the tendency errors of numerical models and therefore reduce the effects of model errors. Applying the OFV approach to the Zebiak-Cane model and correcting the model simulations to agree with the observations, we explore the simulations of EP- and CP-El Nino events and compare them to those simulated by the model without the OFV. The results demonstrate that the Zebiak-Cane model is good at simulating the EP-El Nino events, but fails to describe the behavior of the CP-El Niño events. Therefore, the ZebiakCane model may have large model errors when 
reproducing the observed CP-El Nino events. In fact, when we apply the OFV to reduce the model errors, the model reproduces the observed CP-El Niño events well; furthermore, the related physical variables are also acceptable. Particularly, the simulations of the thermocline depth lead us to believe that the discharge process of the equatorial heat content is not efficient in CP-El Nino events and emphasizes the role of the zonal advection, as found by previous studies. The OFV is clearly useful in reducing the model errors and reproducing the El Niño events using the Zebiak-Cane model.

The OFVs associated with the three CP-El Niño events often exhibit an SSTA pattern with positive anomalies in the equatorial eastern Pacific; therefore, the SST tendency errors occurring in the equatorial eastern Pacific may dominate the uncertainties of the Zebiak-Cane model. A further investigation demonstrates that the OFV induces a "climatological" difference between the model simulations with and without the OFV and provides the "climatological" SST and zonal wind patterns that cannot be described by the Zebiak-Cane model. With the OFV, the ZebiakCane model reproduces the CP-El Nino events well while the model fails to produce the events without the OFV; therefore, the CP-El Nino occurrences may be linked to the SST cold-tongue cooling mode induced by the OFV. Physically, the SST cold-tongue cooling mode and the corresponding zonal wind tend to increase the zonal SST gradient and enhance easterlies over the equatorial eastern Pacific and westerlies over the equatorial western Pacific; these processes lead to the accumulation of warm water in the equatorial central Pacific, finally favoring the occurrence of CP-El Niño events.

$\mathrm{Li}$ et al. (2013) adopted observational data and indicated that the cold-tongue cooling mode may be an important factor for the frequent CP-El Niño occurrences in recent decades. And the theoretical result shown in present paper further confirms that derived from observation and interprets why the cold-tongue cooling mode favors frequent occurrence of CP-El Nino events. Alternative view on the climatological conditions for the frequent occurrences of CP-El Nino events have also been proposed in previous studies (Yeh et al. 2009; Ashok et al. 2007). For example, Ashok et al. (2007) emphasized the difference between the 1958-1978 and 1979-2004 periods and noted that the weakened tropical easterly trade winds that weaken the zonal SST gradient as well as the zonal thermocline are associated with an increase in the CP-El Niño frequency in recent decades. This view indicates a warming trend of the SST in the equatorial eastern Pacific and emphasized its relation to the increasing CP-El Niño frequency. The warming trend in the equatorial Pacific is different from that shown by the seesaw SST pattern (i.e., the cold-tongue cooling mode) demonstrated in this paper. In fact, whether the tropical eastern Pacific has become warmer or colder is still debated (Liu and Huang 2000; Liu et al. 2005; Yeh et al. 2009, 2012; Karnauskas et al. 2009; Deser et al. 2010; Zhang et al. 2010, 2011; An et al. 2012; L'Heureux et al. 2013), presumably due to discrepant observation data, various model outputs and the different time periods studied. Thus, the favorable conditions for increased CP-El Niño occurrences and the explanations of the physical mechanisms are still being explored in-depth.

The simulations of ENSO events, especially the CP-El Nino events, are still challenging due not only to model uncertainties but also to their unclear mechanism. In this paper, we apply the OFVs to the model and reproduce several observed El Nino events. Furthermore, we identify the model bias of the Zebiak-Cane model that affect the CP-El Nino simulation and extract the possible climatological conditions for the frequent CP-El Nino occurrences. The OFV clearly plays a positive role in simulating the El Nino events. However, we note that the OFV here is only applied to the SST equation of the Zebiak-Cane model and may still have uncertainties in the simulations. Therefore, if we calculate the OFVs of the tendency equations for the other variables, the resultant simulations could improve over those in present study. Furthermore, different physical variables may have a much coordinate performance. In any case, ENSO simulations should be further explored by using more complex models, and the OFV approach is expected to play a useful role.

Acknowledgments We thank the two anonymous reviewers for their constructive suggestions and comments, which lead to a significant improvement in the manuscript. This work was jointly sponsored by the National Basic Research Program of China (Nos. 2012CB417404, 2010CB950400), and the National Natural Science Foundation of China (Nos. 41230420, 41176013). Hui Xu is grateful for support by the National Natural Science Foundation of China (No. 41006007).

Open Access This article is distributed under the terms of the Creative Commons Attribution License which permits any use, distribution, and reproduction in any medium, provided the original author(s) and the source are credited.

\section{References}

An SI, Jin FF (2001) Collective role of thermocline and zonal advective feedbacks in the ENSO mode. J Clim 14(16): 3421-3432

An SI, Kim JW, Im SH, Kim BM, Park JH (2012) Recent and future sea surface temperature trends in tropical pacific warm pool and cold tongue regions. Clim Dyn 39(6):1373-1383

Arnold CP, Dey CH (1986) Observing-systems simulation experiments-past, present, and future. Bull Am Meteorol Soc 67(6):687-695

Ashok K, Behera SK, Rao SA, Weng HY, Yamagata T (2007) El Nino Modoki and its possible teleconnection. J Geophys Res 112:C11007. doi:10.1029/2006JC003798 
Atlas R (1997) Atmospheric observations and experiments to assess their usefulness in data assimilation. J Meteorol Soc Jpn 75(1B):111-130

Barber RT, Chavez FP (1983) Biological consequences of El-Nino. Science 222:1203-1210

Barkmeijer J, Iversen T, Palmer TN (2003) Forcing singular vectors and other sensitive model structures. Q J R Meteorol Soc 129(592):2401-2423

Behringer DW, Ji M, Leetmaa A (1998) An improved coupled model for ENSO prediction and implications for ocean initialization. Part I: the ocean data assimilation system. Mon Weather Rev 126(4):1013-1021

Blumenthal MB (1991) Predictability of a coupled ocean-atmosphere model. J Clim 4(8):766-784

Bourassa MA, Smith SR, Brien JJO (2001) A new FSU winds and flux climatology. World Meteorol Organ Publ WMO TD:41-44

Cane MA (1983) Oceanographic events during El-Nino. Science 222(4629):1189-1195

Chen D, Zebiak SE, Busalacchi AJ, Cane MA (1995) An improved procedure for El Nino forecasting - implications for predictability. Science 269:1699-1702

Chen D, Cane MA, Kaplan A, Zebiak SE, Huang DJ (2004) Predictability of El Nino over the past 148 years. Nature 428(6984):733-736

D'Andrea F, Vautard R (2000) Reducing systematic errors by empirically correcting model errors. Tellus A 52(1):21-41

Deser C, Phillips AS, Alexander MA (2010) Twentieth century tropical sea surface temperature trends revisited. Geophys Res Lett 37:L10701. doi:10.1029/2010GL043321

Evensen G (1994) Sequential data assimilation with a nonlinear quasi-geostrophic model using Monte-Carlo methods to forecast error statistics. J Geophys Res 99(C5):10143-10162

Feng F, Duan WS (2013) The role of constant optimal forcing in correcting forecast models. Sci China Earth Sci 56(3):434-443

Jin FF (1997) An equatorial ocean recharge paradigm for ENSO. Part I: conceptual model. J Atmos Sci 54(7):811-829

Kalnay E, Kanamitsu M, Kistler R, Collins W, Deaven D, Gandin L, Iredell M, Saha S, White G, Woollen J, Zhu Y, Chelliah M, Ebisuzaki W, Higgins W, Janowiak J, Mo KC, Ropelewski C, Wang J, Leetmaa A, Reynolds R, Jenne R, Joseph D (1996) The NCEP/NCAR 40-year reanalysis project. Bull Am Meteorol Soc 77(3):437-471

Kang IS, An SI, Jin FF (2001) A systematic approximation of the SST anomaly equation for ENSO. J Meteorol Soc Jpn 79(1):1-10

Kao HY, Yu JY (2009) Contrasting eastern-Pacific and central-Pacific types of ENSO. J Clim 22(3):615-632

Karnauskas KB, Seager R, Kaplan A, Kushnir Y, Cane MA (2009) Observed strengthening of the zonal sea surface temperature gradient across the equatorial Pacific Ocean. J Clim 22(16): 4316-4321

Kim ST, Yu JY, Kumar A, Wang H (2012) Examination of the two types of ENSO in the NCEP CFS model and its extratropical associations. Mon Weather Rev 140(6):1908-1923

Kug JS, Jin FF, An SI (2009) Two types of El Niño events: cold tongue El Niño and warm pool El Niño. J Clim 22(6):1499-1515

Kug JS, Choi J, An SI, Jin FF, Wittenberg AT (2010) Warm pool and cold tongue El Nino events as simulated by the GFDL 2.1 coupled GCM. J Clim 23(5):1226-1239

L'Heureux ML, Collins DC, Hu ZZ (2013) Linear trends in sea surface temperature of the tropical Pacific Ocean and implications for the El Nino-Southern Oscillation. Clim Dyn 40:1223-1236
Li JP, Ren RC, Qi YQ, Wang FM, Lu RY, Zhang PQ, Jiang ZH, Duan WS, Yu F, Yang YZ (2013) Progress in air-land-sea interactions in Asia and their role in global and Asian climate change. Chin J Atmos Sci 37(2):518-538 (in Chinese)

Liu ZY, Huang B (2000) Cause of tropical Pacific warming trend. Geophys Res Lett 27(13):1935-1938

Liu DC, Nocedal J (1989) On the limited memory BFGS method for large scale optimization. Math Program 45(1-3):503-528

Liu ZY, Vavrus S, He F, Wen N, Zhong YF (2005) Rethinking tropical ocean response to global warming: the enhanced equatorial warming. J Clim 18(22):4684-4700

Lord SJ, Kalnay E, Daley R, Emmitt GD, Atlas R (1997) Using OSSEs in the design of the future generation of integrated observing systems. Preprints, 1st symposium on integrated observing systems, 2-7 February 1997, Am Meteorol Soc, Long Beach, CA

Morss RE, Emanuel KA, Snyder C (2001) Idealized adaptive observation strategies for improving numerical weather prediction. J Atmos Sci 58(2):210-232

Rasmusson EM, Carpenter TH (1982) Variations in tropical sea surface temperature and surface wind fields associated with the Southern Oscillation/El Nino. Mon Weather Rev 110(5):354-384

Rasmusson EM, Wallace JM (1983) Meteorological aspects of the El Nino/southern oscillation. Science 222(4629):1195-1202

Rayner NA, Parker DE, Horton EB, Folland CK, Alexander LV, Rowell DP, Kent EC, Kaplan A (2003) Global analyses of sea surface temperature, sea ice, and night marine air temperature since the late nineteenth century. J Geophys Res 108(D14):4407. doi: $10.1029 / 2002 J D 002670$

Roads JO (1987) Predictability in the extended range. J Atmos Sci 44(23):3495-3527

Talagrand O (1997) Assimilation of observations, an introduction. J Meteorol Soc Jpn 75:191-209

Tang YM, Deng ZW, Zhou XB, Cheng YJ, Chen D (2008) Interdecadal variation of ENSO predictability in multiple models. J Clim 21(18):4811-4833

Vannitsem S, Toth Z (2002) Short-term dynamics of model errors. J Atmos Sci 59(17):2594-2604

Weng HY, Ashok K, Behera SK, Rao SA, Yamagata T (2007) Impacts of recent El Nino Modoki on dry/wet conditions in the Pacific rim during boreal summer. Clim Dyn 29(2-3):113-129

Xue Y, Cane MA, Zebiak SE, Blumenthal MB (1994) On the prediction of ENSO: a study with a low-order Markov model. Tellus A 46(4):512-528

Yeh SW, Kug JS, Dewitte B, Kwon MH, Kirtman BP, Jin FF (2009) El Nino in a changing climate. Nature 461(7263):511-514

Yeh SW, Ham YG, Lee JY (2012) Changes in the tropical pacific SST trend from CMIP3 to CMIP5 and its implication of ENSO. J Clim 25(21):7764-7771

Yu JY, Kim ST (2010) Three evolution patterns of central-Pacific El Nino. Geophys Res Lett 37:L08706. doi:10.1029/2010GL042810

Yu JY, Kim ST (2011) Relationships between extratropical sea level pressure variations and the central Pacific and eastern Pacific types of ENSO. J Clim 24(3):708-720

Zebiak SE, Cane MA (1987) A model El Nino-Southern Oscillation. Mon Weather Rev 115(10):2262-2278

Zhang WJ, Li JP, Zhao X (2010) Sea surface temperature cooling mode in the Pacific cold tongue. J Geophys Res Ocean 115:C12042. doi:10.1029/2010JC006501

Zhang LP, Wu LX, Yu LS (2011) Oceanic origin of a recent La Ninalike trend in the tropical Pacific. Adv Atmos Sci 28(5):1109-1117 